\title{
Tristes tópicos cervantinos: periferia e identidad en algunos acercamientos posmodernos a Cervantes
}

\author{
HÉCTOR BRIOSO SANTOS*
}

Desde hace varios años, un grupo de cervantistas norteamericanas ${ }^{1}$ ha lanzado la tesis de que Cervantes escribió su narrativa sugestionado por la existencia de las entonces llamadas Indias Occidentales. Esas investigadoras sostienen que ese novelista leyó las crónicas americanas y las empleó como fuentes, sobre todo en su creación de los dos Quijotes, las Novelas ejemplares y el Persiles. Mary M. Gaylord ha resumido así la hipótesis de trabajo de su colega Diana de Armas Wilson: "Basándose en el inventario de referencias y conocimientos indianos hechos por estos investigadores [Irving Leonard, Jorge Campos, Valentín de Pedro, José Toribio Medina y Raúl Porras Barrenechea, nombrados por ese orden], Wilson propone que la hostilidad cervantina hacia los libros de caballerías es el vehículo de una crítica a la conquista americana" (2006, p. 81). La misma Gaylord imagina una "lectura indiana, sin duda voraz" de Cervantes (2006, p. 85) y Wilson incluso aventura que "Cervantes writes about barbarians who are both European and American" en su Persiles y que éste posee una "americanized Overture" que apunta hacia "the massive New World 'transnational' phenomenon taking place as Cervantes wrote" (1999b, pp. 56-57). En suma, esas profesoras suponen la existencia de un

* Universidad de Alcalá.

1. Principalmente han lanzado esta propuesta las profesoras Diana de Armas Wilson, Mary Malcolm Gaylord y, en menor medida, Luis Correa Díaz. Me centraré sobre todo en las publicaciones principales de esta línea de los estudios culturales y, en particular, en los trabajos de las dos autoras mencionadas, y dejaré para otro momento, por falta de espacio, las teorías revisionistas de William Childers y de otros investigadores próximos a las tesis de Wilson y Gaylord. 
novedoso "Anglo-American Cervantes" y un "Americanist Cervantes", esto es, nada menos que una suerte de Cervantes americanista ${ }^{2}$.

En estas páginas retomaré el hilo de mis anteriores acercamientos a esta escuela o tendencia hermenéutica. Me propongo oponer ahora varios reparos nuevos a sus métodos, sólo que ahora desde una óptica más metacrítica, es decir, de crítica de la crítica cervantina, sobre todo en lo que hace a las bases políticas y filosóficas de ese supuesto Cervantes americanista redivivo o resucitado.

Las alusiones a América que hace el escritor de Alcalá en sus obras han sido catalogadas por esas autoras en dos categorías: por un lado, "figuras y temas esparcidos en el Quijote" y en otras obras en forma de "mención directa", y por otro, unas presuntas alusiones anónimas, una "nameless presence" de los "New World super-heroes" y unos "implied New World models for Don Quixote's later-day chivalric Enterprise"3. Ya aquí surgen dos inconvenientes, según mi criterio: las primeras son escasas y las segundas son, a menudo, especialmente dudosas y sólo aceptadas de modo explícito por las mismas estudiosas que las aducen. En ese punto nuestras autoras alegan que la verdadera influencia americana en el novelista manco ha sido omitida, soslayada o ignorada por la crítica precedente y que Cervantes es un autor misterioso y enigmático, que requiere hábiles descubridores y zahoríes capaces de "declarar el secreto a voces de sus afinidades americanas". De ahí se pasa a afirmar la "omnipresencia" de estos temas indianos y su indudable "elocuencia" (id., p. 84), pero también la necesidad de un desciframiento, de una tarea de traducción, que estas investigadoras se han propuesto emprender en beneficio del resto de los hispanistas.

Desde la orilla opuesta de este razonamiento, entiendo que esa anonimia y esos enigmas son, en realidad, la consecuencia de los excesos interpretativos de las exégetas en cuestión, que suponen americanismos donde éstos no existen: la Isla Bárbara no es ningún enclave americano, aunque Cervantes pueda (o no) haberse inspirado en alguna crónica de Indias para dotar a esa isla de un cierto color antropológico de verosimilitud exotista ${ }^{5}$. La inspiración de Cervantes en Ercilla a la hora de escribir su Quijote ${ }^{6}$ y la idea de que el

2. Wilson, 2003, pp. 19 y 48, respectivamente. Estas etiquetas coinciden pintorescamente con las que Mark Twain solía aplicarse a sí mismo (véase el trabajo de Henry B. Wonham de 2005, p. 159).

3. Respectivamente, Gaylord, 2006, pp. 82-83, y 2007, pp. 89 y 91.

4. Gaylord, 2006, p. 83; la cursiva es mía.

5. Puesto que ya he ido refutando en otras publicaciones muchos de esos loci cervantinos presuntamente americanos, añadiré aquí sólo algunos datos expresivos: los documentadísimos apéndices I, IV y XIII de la edición de Carlos Romero Muñoz del Persiles no sólo no confirman sino que desmienten las aducidas fuentes americanas de otros tantos pasajes del comienzo de esa novela. La misma Gaylord afirmaba en 2007 muy claramente que "References to books which deal with Spain's New World experience are extremely rare in the Quijote; veiled allusions, few" y hablaba de una cervantina "reticence" hacia el asunto Americano en esa obra (p. 81); a la par que explicaba que "the Discoverer of 1492 is never mentioned in the Quixote and the invader of Mexico does not make his cameo appearance until the second volume" (p. 89).

6. Además de la mención ercillana en el escrutinio de la librería de don Quijote (I, 6; p. 86) y de la presumible inspiración en La Araucana del famoso corte narrativo del final del capítulo octavo 
caballero homónimo modela sus discursos sobre las arengas de Hernán Cortés, las cartas colombinas y los escritos lascasianos, dos hipótesis argüidas por Gaylord (2007, pp. 81 y 89-91), son sendas suposiciones sin base probatoria alguna; igual sucede con la ocurrencia de comparar los desafíos quijotescos con el siniestro Requerimiento indiano (id., p. 90), etcétera ${ }^{7}$.

Henos aquí, pues, en pleno terreno paradójico: Cervantes, como ellas mismas reconocen, no alude apenas a América, pero sus obras hierven de fuentes, de asociaciones y de alusiones americanas, casi siempre encubiertas. Gaylord se instala justamente en el filo de la navaja cuando escribe, por ejemplo, sobre el Quijote y su autor que

If explicit reference scarcely suggests admiration (most of the book's rare New World references make it a mine of material riches, while only one cites an instance of heroism), the historical author must have been as ambivalent as he was critical with respect to the American dream he once hoped to share. From the standpoint of literature, his view would have been no less complex. For, while he surely did not admire as exceptional aesthetic artifacts the American epics he declined to place in the hidalgo's library or on his own avowed reading syllabus, he must have found them overflowing with grist for his parodic and satiric mill (2007, p. 91).

Y, sin embargo, a pesar de la taracea de citas expuestas o invocadas por estas autoras, se aducen muy pocos, poquísimos paralelos textuales que puedan abonar verosímilmente semejantes tesis. Como en otros lugares ya he dedicado cierta atención a esas presuntas muestras de americanismo cervantino, cumple ahora establecer los motivos de esta moderna mixtificación.

Para empezar, el caso del novelista de Alcalá, usufructuado así por un pequeño sector del cervantismo posmoderno, tiene un interés añadido: nuestro autor no es el típico escritor menor, subalterno y periférico generalmente escogido y rescatado por los adalides de la nueva ola crítica. Más bien, aunque oportuno por su conocida heterodoxia ${ }^{8}$, resulta ser una figura demasiado central, y hasta eurocéntrica ${ }^{9}$, orientada primero hacia el Mediterráneo -luego volveré sobre esto- y después hacia el lejano norte del Persiles. Y ésta puede ser precisamente la clave del problema: al descentrar y volver periférico en

de la primera parte de esa novela (p. 104), por ejemplo, Jorge Albistur ya había insinuado vagamente en un artículo de 1989 que únicamente la conquista de América “i(..) podía por entonces explicar una quijotada!" (p. 66).

7. Este proceder puede contrastarse con la sutileza que exhibe Moisés R. Castillo cuando, en un estudio reciente (2009) del indígena americano en trece piezas del teatro áureo, argumenta que Lope de Vega pudo conocer la obra de Las Casas (p. 58), para luego desmentir el fondo de ese lascasianismo lopiano al interpretar El Nuevo Mundo descubierto por Cristóbal Colón del Fénix de los Ingenios (p. 63).

8. Cf. Castro, que ya afirmaba en 1925 que «Cervantes formulaba graves problemas, artística y filosóficamente" (1987, p. 9); pero también deben consultarse obligatoriamente: Marcel Bataillon (1966, cap. XIV, sección IV) y Close (1998, pp. lxvii-lxxxvi).

9. Esa es su posición, al menos, en el capítulo 5 de la Segunda parte, titulada "La edad aristocrática" de El canon occidental de Harold Bloom, de 1994, una verdadera Biblia de la antimodernidad a la par que un libro dogmáticamente eurocéntrico y anglocentrista. 
cierto grado a ese escritor, se logra anexionar un nuevo e importante territorio para la llamada subalternity ${ }^{10}$, esa categoría tan característicamente posmoderna, al tiempo que se coloca al Manco de Lepanto en una oportuna posición marginal o fronteriza. Y esa periferia, en el nuevo canon de moda, resulta ser paradójicamente el centro de las preocupaciones del crítico, que funge como un investigador ecuménico a base de elegir temas y autores de cualquier lugar del orbe y tornarlos así occidentales mientras él mismo se orientaliza figuradamente y conjura cualquier riesgo de centralismo europeísta. Cervantes se revela entonces como el epicentro de ese debate tan característicamente posmoderno como es el de los insides y los outsides, el dentro y el fuera, el este y el oeste, el oriente y el occidente, las fronteras y las nacionalidades ahora alegremente deconstruidas.

En todo caso, debe repararse en que estamos ante un falso cosmopolitismo o un universalismo de pega, justamente algo que Fredric Jameson ya definía en su crítica a la posmodernidad de 1986, no sin cierto deje despectivo, como "some general liberal and humanistic universalism" (p. 77). Pues, en realidad, todo este esfuerzo de reivindicación oculta un sentimiento de culpa eminentemente occidental y está forzosamente sesgado por un humanismo occidentalista. Es como si se reviviera la curiosa paradoja descrita por Edward Said: Joseph Conrad denunció los males del colonialismo pero no pudo liberarse de la cosmovisión colonialista. Ya apuntó Carlos J. Alonso que "at the precise moment that Spanish American intellectuals asserted their specificity or made a claim for cultural distinctness, they did so by using a rhetoric that inevitably reinforced the cultural myths of metropolitan superiority" y dictaminó que "this contradiction resides at the root of Spanish American cultural discourse and has dictated until very recently the contorted intensity of its rhetorical force" (1996, 228). Algo parecido sucede, mutatis mutandis y a menor escala, con nuestras estudiosas, pese a las protestas de Gaylord contra el "scholarly provincialism" o los "national interests [that] have long favored the patriotic reading" que, según ella, han perjudicado a los estudios de Siglo de Oro y coloniales (1996, p. 223), dado que la alternativa que nos presenta esta nueva escuela crítica no es una reorientación geográfica que situaría teóricamente el cervantismo entre esos "endless movements of transculturation in Our Americas" (1996, p. 127) que ha descrito Doris Sommer o en la línea de los "multilinguistic and multicultural project identities" que reclama Mariscal (2001, p. 240), sino una doctrina que proyecta en la práctica la obra de Cervantes hacia una suerte de backyard norteamericano y anglófono de los estudios americanistas, suscitando apenas un provincianismo o un localismo de signo distinto, aunque más sofisticado.

10. La palabreja fue inventada por Antonio Gramsci y traducida al neo-inglés posmoderno por Fredric Jameson (1986, p. 76). Los neologismos son numerosos, tanto en inglés como en castellano, en el seno de esta escuela de cervantismo y de americanismo herméticos: lettered, imper(v)ious, reimaginar, transnacionalizar, bridge-crossing, self-translating, etc. 
Expliquémonos: en primer lugar, como Mariscal lamenta en su artículo citado, la tradición de estudios culturales en castellano es ignorada por los estudios culturales anglo-americanos en inglés ${ }^{11}$. Entonces es evidente que nuestras cervantistas desean, a base de politizar al autor objeto de estudio, invadir lo que parece ser un cercado ajeno y asimilar a Cervantes a los más prestigiosos cultural studies anglos. Pero no sólo eso, porque también le hacen un guiño a los estudios de colonialismo y de identidad latinoamericana, al sugerir la americanidad -ambigua palabra- de Cervantes. Según mi criterio, las dos cosas son poco viables, pues se fundan, como he demostrado en varios artículos previos, en conjeturas desatadas, armadas unas sobre otras, y en una telaraña de citas mutuas entre las adeptas de la idea, además de en un repertorio de lugares comunes identitarios, culturalistas y típicamente anglosajones que le cae muy lejos al autor del Quijote.

Y no es inútil sugerir, además, que en esa alienación de Cervantes pueden tener algún papel la moderna leyenda negra o mala fama institucional en Norteamérica de los estudios en castellano que Mariscal describe tan acertadamente (2001, p. 234), además de la consabida Leyenda Negra contra las things Spanish desde hace siglos. Recordemos que el cervantismo y el siglodeorismo convencionales han servido para promover la literatura española peninsular en las universidades de los EE.UU. durante un siglo, aunque ahora esos mismos campos de estudios sean denostados por el latinoamericanismo más beligerante. La solución, desde hace un par de décadas -a la zaga de los trabajos conflictivos de Américo Castro, Stephen Gilman, A. A. Sicroff et alii-, parece haber consistido en preferir como objeto de análisis las obras de ciertos literatos menos sospechosos de españolidad, si no raros, problemáticos o disidentes, entre los cuales hallamos a los presuntos judíos Fernando de Rojas y Cervantes, géneros enteros como la ascética, la mística y la picaresca; o a sedicentes autoras feministas como María de Zayas, y a las escritoras en general, puesto que, por definición, eran marginadas por una sociedad patriarcal ${ }^{12}$. Y la elección de autores y sobre todo de autoras laterales permite sortear los reparos ideológicos contra la época y el país en cuestión.

Otra solución, sumamente eficaz, para evitar el veto a los estudios peninsularistas es justamente la de vincular esos estudios con lo americano, lógicamente de moda en esas latitudes. De ahí que los casos más conspicuos de intelectuales que se ofrecen como objetos de estudio ideológicamente idóneos sean, naturalmente, los autores indianos, dado que se presume que son de sí fronterizos, transculturales y hasta mestizos en algún caso, en una escala que va desde los emigrados nacidos en España hasta los cuarterones aristocráticos como el Inca Garcilaso, el más excelso de todos los casos posibles para el revisionismo neocolonial. Lo esencial ya no es entonces la mezcla de las sangres entre las castas judía y cristiana, sino el trasiego

11. Mariscal cita (p. 234) esa idea, originalmente formulada por Jon Stratton y Ien Ang en 1996.

12. La propia Wilson ha transitado desde los estudios de feminismo áureo hacia su actual deriva americanista: véanse sus estudios de 1983, 1986 y 1991, por ejemplo. 
geográfico, el cruce de las fronteras y los océanos en pos de transculturalidades y puentes figurados. De ahí que del Cervantes español y esencialmente local del XIX -el de los rancios debates del nacimiento sevillano o cordobés; el del vetusto positivismo de los modelos reales y la tumba de don Quijote, etc.- hayamos pasado a uno más problemático a mediados del XX -descendiente de judeoconversos, social y políticamente crítico y teológicamente escéptico- $\mathrm{y}$ a la postre a una última reencarnación mestiza y posmoderna de Cervantes como un outlaw al que se le prohíbe emigrar a Indias y como el adalid de una cultura subalterna y transcultural como la latinoamericana ${ }^{13}$. La españolidad de Cervantes no estuvo en tela de juicio ni siquiera para Castro, que reputaba como españoles a los judíos y a los conversos, pero sí lo está ahora, cuando las cervantistas citadas proponen que el autor del Quijote es un ejemplo ideal de border-crossing, por no decir un espécimen de las otras cuatro recetas mágicas del mantra culturalista: traducción, rearticulación, transcodificación y transculturación.

El lector debe considerar si no estamos ante un caso de alienación y de improvisado juicio político a través de los siglos. Como es lógico, no propongo aquí elevar nuevos muros ni fronteras, pero tampoco parece oportuno convertir a Cervantes en un mero transmisor o portavoz de consignas de moda en países y culturas muy alejadas de su circunstancia histórica. No deberían preocuparnos tanto las necesidades ideológicas del presente como las exigencias puramente lógicas de una historiografía consecuente. El papel de un escritor del XVII en un debate moderno contra el neoimperialismo y el neoliberalismo se nos antoja más bien escaso y del todo anacrónico. Y, pese a su personal credo socio-político, los cervantistas no deberían encajar precisamente en el cometido que Mariscal define como el de unos "cultural studies workers committed to progressive change attempted to interpret the cultural production born of such unsettled circumstances [las de los emigrantes] and the circumstances themselves", ni debería preocuparles, a la hora de repasar críticamente la producción cervantina, la tarea del "engagement of cultural Studies with larger social issues" que ese profesor reclama para los que llama, en frase impagable, los trabajadores de los estudios culturales (2001, p. 236). Sin embargo, sus colegas Wilson y Gaylord sí han emprendido denodadamente lo que parece "a deliberate transgression of institucional and ethnic boundaries and a broadening of the collective Project" (Mariscal, $i d$.). Y lo extraño, en definitiva, es que nuestras estudiosas hayan aplicado a un autor peninsular español estas consignas pensadas para los chicanos de Los Angeles y del sudoeste norteamericano. Cervantes, desde luego, no forma parte de una nacionalidad dicotómica que actúe hoy como una barrera destinada a la dominación de grupos étnicos y sus presuntas etnicidad problemática o 
transculturalidad, por muchas vueltas que les demos, no van a contribuir ni a democratizar el futuro ni a ningún proyecto marxista posmoderno ${ }^{14}$.

En el fondo, asistimos a una serie de estrategias de enajenación y de apropiación verdaderamente llamativas y a las que ninguna tradición crítica nacional ha permanecido totalmente ajena: si el recientemente fallecido Isaías Lerner se refirió hace pocos años a lo que denominó el "reiterado solipsismo característico (...) de generaciones peninsulares de otros tiempos" y que afecta a los hispanistas españoles, que ignoran, según él, los frutos más granados del cervantismo del Cono Sur (p. 256), no es menos notable la resistencia de esos mismos españoles tanto al estructuralismo como a las nuevas modas culturalistas y étnicas post-estructuralistas, una alergia que estas páginas pretenden razonar en parte. Y, desde luego, a esas reacciones adversas cabe añadir el evidente aislamiento -o solipsismo, para aprovechar la frase de Lerner- de los estudios de hispanismo y colonialismo en Norteamérica, abocados a un camino sin salida.

Por otra parte, a pesar de los esfuerzos de un sector de los americanistas de los siglos XX y XXI por reducir o soterrar el valor de la aportación española a la cultura americana en razón de consideraciones de tipo político e identitario, es justo subrayar que la escuela de seguidores de Wilson en realidad se mantiene en una posición difícil y contradictoria entre la defensa de la colonización cultural y la repulsa hacia ésta, puesto que, para avalorar lo americano precisamente se ven impelidos a destacar el peso de Cervantes y lo cervantino - ergo, del llamado Siglo de Oro- en esas tierras, además de subrayar a su modo lo colonial. En definitiva, se ven en la encrucijada bien descrita por el citado Alonso: de un lado, "the naïveté of autonomy"; de otro, "the dead end of resistance" (1996, p. 234). Y en ese punto coinciden sin quererlo con los presupuestos generales del ensayo clásico, y quizás un punto reaccionario, de Antonio Tovar, Lo medieval en la conquista, donde el ilustre filólogo vallisoletano enumeraba y razonaba con bastante justeza los logros $-\mathrm{y}$ los defectos- de la colonización cultural del Nuevo Mundo por una España, según él, tardomedieval ${ }^{15}$. Y esa coincidencia nos permite destacar tanto la coherencia interna esencial del estudio harto documentado de Tovar como la ambivalencia o la contradicción de fondo de las tesis de nuestras cervantistas de nuevo cuño. En realidad, no podemos evitar la sensación de que esta contradicción es inherente a una parte del siglodeorismo norteamericano, sumido hoy en una cierta crisis de identidad: si obedece a los dictados del canon

14. Sigo parafraseando algunas expresiones de Mariscal (2001, pp. 236-237). Barbara Simerka habla, por ejemplo, sin tapujos de una poética materialista y de un materialismo cultural, en alusión clara al materialismo dialéctico, y afirma principios marxistas en el capítulo inicial de su libro de 2003.

15. Véanse, por ejemplo, las frases finales de uno de sus capítulos en las pp. 48-52. Aunque se trata de unas consideraciones que nuestras estudiosas norteamericanas a buen seguro desmentirían con cierto enojo, es de destacar que ellas mismas se han apoyado en el dato de la exportación de Quijotes a Indias que Tovar consideró - con razón- como un argumento en abono de su tesis favorable a la colonización ( $c f$. sus páginas 32-33). Compárese este balance con los que hace Todorov en sus pp. 190,256 , etc. 
posmoderno, se diluye en un caos ahistórico y ageográfico; si no los secunda, también perece casi sin remedio, puesto que se verá obligado a traicionar las consignas políticas que se ha autoimpuesto. De suerte que la tendencia a la refundación novomundana de los estudios áureos no pasa de ser un salto a la desesperada, en medio del vacío y la fragmentación de la posmodernidad.

Pues bien, la elección del presunto escritor conflictivo Miguel de Cervantes no se justifica suficientemente por su aparente posición marginal: ni lo fue en su vida tanto como se ha supuesto ni sus coordenadas intelectuales y personales lo sitúan en una latitud tan periférica y fronteriza como se pretende. Precisamente nuestras autoras se han esforzado denodadamente en enajenarlo de la vida española, occidentalizarlo y politizarlo todo lo posible, a mi modo de ver un tanto infructuosamente. Evidentemente no fue un escritor áureo clásico demasiado convencional, pero sus ambigüedades y sus silencios, a los que su época lo forzaba, no nos autorizan a convertirlo románticamente en un subversivo, en un ejemplo de escritor protestatario que abrazara sin titubeos las causas del desposeído, del morisco y del indígena. Lope de Vega o Quevedo, nada sospechosos de poner en duda el orden ideológico de su tiempo, incurrieron en parecidas veleidades momentáneas en favor de pueblos amerindios, e incluso lo hicieron con más claridad que Cervantes, y, curiosamente, ni eso los ha convertido en adalides de la modernidad ni las mismas estudiosas aquí tratadas se han sentido tentadas de hacerlo. De modo que no parece el Manco Sano, que adquirió su manquedad en Lepanto y en lucha contra las galeras otomanas, demasiado apto para formar parte de un proyecto que podríamos, siguiendo a Mariscal, rubricar bajo el actual lema culturalista norteamericano de "teaching for progressive social change" (2001, p. 240), un plan al que los así llamados "cultural studies workers" sin duda contribuyen con su particular doctrina de "pedagogy and activism" (ibid.). Pues, pese a sus bien conocidas opiniones, formuladas casi siempre con una sofisticada ambigüedad, no podríamos calificar a Cervantes como un rebelde transcultural y apátrida capaz de protagonizar nada menos que el siguiente trabalenguas: "the exclusión of the excluders by the excluded" (id.) ${ }^{16}$. Según analizaré después, el trasfondo de estas tesis multiculturales reside, probablemente, en el perverso y contradictorio relativismo cultural sostenido por Claude Levi-Strauss y sus numerosos epígonos ${ }^{17}$.

Otro punto de partida de esta escuela de verdadero quijotismo mítico o cervantismo mágico ${ }^{18}$ parece ser la confusión deliberada y muy posmoderna, aunque no nueva, de dos terrenos geográficos y culturales distintos, como son las crónicas y la literatura de ficción; porque aquéllas se escribieron y trans-

16. Aunque el comienzo del texto parezca menos doctrinal, las tres últimas páginas del artículo citado de Mariscal son, de hecho, un alegato en defensa de las ideas progresistas en las universidades norteamericanas. Curiosamente, no llega a abordarse convincentemente la cuestión planteada por el título.

17. Véanse los reparos a sus teorías opuestos por Tzvetan Todorov (1991) y Juan José Sebreli (2007, cap. 5).

18. Tomo la segunda formulación de La cervantiada de Julio Ortega (1993, p. 123). 
mitieron como informes o como divulgación científica, generalmente desde las entonces llamadas Indias Occidentales, mientras que la literatura, entonces esencialmente peninsular, tenía unos marcados designios estéticos y se alejaba, a veces notablemente, de la realidad referencial, que es precisamente el norte hacia el que, por el contrario, tienden las crónicas.

Esta confusión es siempre interesada, puesto que con ella muchos historiadores de la literatura hispanoamericana han pretendido anticipar artificialmente el comienzo de la tardía literatura de ese continente, incorporando a ella a muchos autores y obras fundamentalmente españoles y que pertenecen a la historia o al informe científico, geográfico o etnográfico ${ }^{19}$. Ha sido éste un designio tradicional de los americanistas de variado signo, que a menudo se han apoyado en el argumento de la calidad estilística, un hecho habitual, por no decir casi universal, de muchos escritos de la época. Pese a este factor igualador, todavía cabe hacer en este punto una reflexión más, pues el citado Jameson ya nos prevenía en 1986 contra la falsa noción posmoderna de que todos los textos son iguales para el crítico, que no tiene derecho a discriminar unos frente a otros: "Nothing is to be gained by passing over in silence the radical difference of non-canonical texts" (p. 65). Andando el tiempo, no sólo se comprueba que Jameson tenía razón, sino que, además, hoy podemos evaluar las consecuencias de esa labor de zapa del canon, o como se le quiera llamar, emprendida hace desde hace por lo menos treinta años por un ejército de desorientados hermeneutas promotores de las minorías y de los territorios y los autores marginales ${ }^{20}$.

Pues bien, Wilson y Gaylord recurren también a las crónicas como otra posible conexión cervantino-americana y se valen para ello de diversos subterfugios. La primera presentaba esta idea, por ejemplo, en un artículo de 1999a: en su p. 41 proclamaba casi sin pruebas que "los libros de caballerías, las utopías, la etnohistoria y la épica de batalla colonial (...) facilitaron la creación de la novela cervantina"; y después, en la sección 1.2, acerca de las crónicas americanas, de su libro de 2003, asentaba que "there is no doubt that Cervantes was familiar with some of the Chronicles of the Indies" (p. 24), pero se limitaba ahí a hacer sin más una lista de tales libros publicados en tiempos de nuestro escritor (pp. 26-27) ${ }^{21}$ y a difuminar las fronteras de ese género de la crónica, que consideraba ya como una "distended family", en la que llegaba a incluir hasta las bulas papales, los corpus legales, nada menos

19. Las exposiciones más inteligentes de esta tesis de la amalgama de crónica y literatura pueden verse en Walter Mignolo (1981) y, a su zaga, en Gaylord (1996a), según veremos enseguida. $C f$., también para esta cuestión, algunas páginas de mi América en la prosa... (pp. 23-27).

20. Aparte de las filípicas de Bloom, véase sobre esto el artículo de Jesús G. Maestro (2009) y el reciente veredicto de Jorge Mojarro Romero, que sentencia, frente al todo vale de los adalides de la posmodernidad, que "todo no vale" (2009).

21. Belisario Betancur ha recurrido al mismo argumento fallido de la simple coincidencia cronológica (2008, p. 3). Cf., en cambio, Daniel Eisenberg, que anotaba en su estudio provisional: "No vemos cómo tratar con la precisión necesaria ni las crónicas de Indias ni las relaciones que se publicaban de la guerra de Chipre, la batalla de Lepanto y otros sucesos contemporáneos" (p. 49), textos todos que no sabemos -y quizás nunca sabremos- si Cervantes leyó o no. 
que las comedias pertenecientes a lo que ella denominaba el canon americano y -reconociendo la distancia- la desigual pieza El rufián dichoso (p. 24), aunque es de suponer que esa especie canónica debería abarcar sobre todo las comedias monográficas de asunto colonial, tan bien conocidas por la crítica especializada como poco citadas por nuestras estudiosas.

Sin embargo, harto inexplicablemente, Wilson sólo menciona como inspiración de Cervantes dos crónicas de Indias: La Araucana de Ercilla (p. 25), que no es exactamente una crónica ni siquiera según sus propios criterios ${ }^{22}$, y la historia de Dávila Padilla, fuente directa de El rufián dichoso (p. 24). Gaylord es más audaz, pues ha aducido, sin entrar en demasiados detalles, como lecturas cervantinas, obras de Colón, Las Casas y sobre todo el Hernán Cortés de López de Gómara $(2007)^{23}$. Pero se trata siempre de parecidos harto difusos: el Quijote comparte con las crónicas americanas, según aclara la misma Gaylord, temas tan vagos y tópicos como el de la Edad de Oro, las islas, las ceremonias de posesión (se entiende geográfica), la rivalidad guerrera o religiosa, las armas y las letras, la historia verdadera, la fama, la fortuna, el buen gobierno o la esclavitud (2007, p. 90); y a otro nivel, "in the fulsome speech of New World super-heroes, in the overreach of their language and the do-it-yourself approach to the monumentalizing business of History and Poetry, [Cervantes] found quixotic inspiration for the wordiness of our favorite character" (id., pp. 91-92).

Acaso esta pretendida abundancia de posibles modelos cervantinos concretos entre las crónicas se deba en parte a que la definición de ese género se ha distendido tanto que todo puede ser y puede no ser crónica de Indias, pero también hay que pensar que, a despecho de los argumentos capciosos de Wilson, Cervantes debió leer muy pocos de esos textos, por mucho que ampliemos el corpus de lo legible en términos de vaga historiografía. Es decir: por un lado, esa cervantista halla la cuadratura del círculo del americanismo de nuestro escritor en un género deliberadamente indefinido y para-literario en el mejor de los casos, pero por otro se ve obligada a reconocer tácitamente que ese difuso constructo posmoderno no tiene una clara vinculación con la obra cervantina.

Más peregrinos resultan los razonamientos de Gaylord para amalgamar crónicas y literatura: el hecho de que tanto los autores de ficción como los historiadores áureos se sirvieran del mismo marbete de historia verdadera para sus textos (1996a, pp. 215-222), la noción ya aludida de que las fronteras

22. Ella misma parecía llamarla en 1999 una "épica de batalla colonial” (1999a: p. 41). En su día, Marcos A. Morínigo y Lerner pusieron en su justo punto el asunto del pseudohistoricismo ercillano y dejaron claro que tanto el propio Ercilla como ellos mismos distinguían perfectamente lo histórico de lo poético (1979, I, pp. 25-32 y 35). Hoy puede leerse una ponderada síntesis de la cuestión política ercillana, por ejemplo, en la entrada Araucana de Alberto Rodríguez Carucci en el Diccionario enciclopédico de las letras de América Latina.

23. Su idea no es nueva, pues ya la había anunciado en una comunicación de 1995 bastante ayuna de datos concretos y finalmente editada en 1998 bajo el título de "El Siglo de Oro y las Españas: propuesta de una nueva lectura americana del Quijote". 
científicas y genéricas puedan ser en realidad el resultado de un provincianismo de los estudiosos (id., p. 223) y la vaporosa idea de que toda la literatura del Siglo de Oro es posterior al Descubrimiento colombino (id., pp. 224-225). Las tres explicaciones son harto especiosas: curiosamente, en todo ese artículo polémico no abundan en absoluto ni las citas literarias áureas ni las de las crónicas americanas, un indicio claro de que apenas existen los presuntos vínculos sugeridos por Gaylord. Las crónicas y relaciones indianas fueron, en ese período, una lectura destinada a especialistas, que no circularon masivamente y que Cervantes no debió manejar con la profusión que se pretende porque ni las necesitaba para nada ni parecieron interesarle especialmente. Según mi entender, que ese novelista hable de historia verdadera poco o nada significa en relación con las crónicas y sí en relación con los libros de caballería, el oficio de novelar y el aristotelismo. Y, finalmente, cae de su peso y ahí está la bibliografía especializada para demostrarlo, que la posterioridad respecto al Descubrimiento no tiñó de un nuevo y general americanismo ni las obras de Cervantes ni las de otros autores, literarios o no. Pretender otra cosa a todo trance y a contrapelo de los textos es retornar al americanismo y al indigenismo militante de 1992 o incluso regresar, malgré Castro, al cervantismo esotérico y simbolista del siglo XIX.

Y todavía sorprendemos a Barbara Simerka en una finta metodológica más astuta cuando incluye las comedias de indiano entre las piezas que representan de forma alternativa la conquista militar de las Indias (2003, esp. p. 7), pero de nuevo estamos ante otra confusión innecesaria de categorías muy distintas de textos teatrales: de una parte, la comedia de capa y espada o de enredo, una especie o categoría muy bien establecida en la que a menudo figuran indianos, y de otra, la pieza heroica de tema y tono solemne y de contenido político, hagiográfico o militar y que excepcionalmente sucede en las Indias Occidentales.

Una vez confundidas ambas esferas, la de las crónicas y la de la literatura, por muchos historiadores con la intención, loable pero a mi ver equivocada, de ampliar la historia de las literaturas nacionales americanas ${ }^{24}$, resurge con fuerza la vieja pretensión de difuminar también las fronteras geográficas, pro-

24. El asunto es casi tan viejo como los intentos iniciales de hacer historia de las literaturas nacionales ultramarinas, aunque el criollismo y el nacionalismo del XX lo han exacerbado considerablemente. Pensemos en las explicaciones que ofrecía en 1939 Agustín Yáñez en su introducción a una antología de crónicas americanas: "Las crónicas de la conquista, de acuerdo con la idea de mexicanidad acabada de sustentar, son los primeros monumentos de la literatura nacional"; aserto que iba acompañado de la indispensable apelación al factor de la naturaleza y la tierra, único argumento capaz de justificar en parte la mexicanidad de Francisco López de Gómara, Pedro Mártir de Anglería, Hernán Cortés, etc. (1987: vii). Aun así, Yáñez deslindaba con precisión a los cronistas que no pisaron el Nuevo Mundo de los que lo hicieron, que son los que le interesan (p. x); y, por supuesto, Cervantes no aparece en parte alguna de su texto. Morínigo, más tradicional, distinguió neta y prudentemente historiografía y literatura de imaginación (1946, p. 24). Estos esfuerzos bien podrían examinarse y deconstruirse hoy por medio de métodos más sólidos que los empleados por nuestras cervantistas americanas en su propia construcción ideológica. Propongo, por caso, que se les apliquen los principios críticos expuestos y empleados por Jon Juaristi en sus escritos sobre la construcción de la identidad vasca [véase, por ejemplo, El linaje de Aitor. La invención de la tradición vasca (1987), especialmente pp. 18-21]. 
clamando que los contextos geográficos son intercambiables ${ }^{25} \mathrm{o}$ incluyendo entre los autores hispanoamericanos a los españoles emigrados a Ultramar como Alonso de Ercilla o Juan Ruiz de Alarcón, Juan del Valle y Caviedes o ciertos cronistas, entre otros ${ }^{26}$. Ambas campañas forman parte de un visible esfuerzo de reivindicación de la identidad hispanoamericana frente a la de la antigua metrópoli. Pero reparemos en que esta supuesta integración tiene dos velocidades: cuando así conviene al proyecto identitario, esos y otros autores son americanos; cuando no, es decir, siempre que se percibe que dicen algo inconveniente, los mismos escritores se tornan súbitamente peninsulares. De manera paralela, los cronistas o el mismo Ercilla pueden oscilar oportunamente entre lo literario y lo histórico o entre lo hispanoamericano y lo españolcolonial. En resumidas cuentas, muchos de estos intentos resultan ser, al fin y a la postre, una nueva campaña de forzado mestizaje -para usar su misma palabra, según veremos enseguida- cultural y de géneros, algo muy oportuno cuando se trata de promover las consignas de una multiculturalidad avant la lettre en una época como el Siglo de Oro.

El paso final de esta tendencia es, como ya habrá adivinado el lector, el de convertir a Cervantes en algo parecido a un voluntarioso cronista de Indias: un testigo, un aficionado a las things American o un sutil promotor de la curiosidad hacia Ultramar ${ }^{27}$. Quizás sea éste el motivo de que en los estudios de nuestras autoras menudeen las alusiones a Ercilla ${ }^{28}$, que sí tuvo, aparentemente, esa disposición o esa curiosidad (aunque sorprende siempre que se olviden del indiano parcial Mateo Alemán), e indudablemente el afán de Wilson por emparejar a Cervantes con el Inca Garcilaso en su libro de 2003 sólo puede tener esta explicación ${ }^{29}$, especialmente si tenemos en cuenta que Juan Marichal consideró a ese historiador peruano como "the first true Latin American" en el sentido de ser el pionero en proclamar el clasicismo indiano, esto es, el parentesco entre lo americano y la antigüedad grecolatina

25. Barbara Fuchs, por ejemplo, sostenía esa idea en un artículo de 1997 acerca de La tempestad de Shakespeare.

26. Más ponderado resultó el acercamiento al problema de los críticos de hace medio siglo: Urtiaga hizo un recuento de los que llamó los "escritores indianos de nuestro Siglo de Oro" y consideraba dotados de lo que denominó, con cierto voluntarismo crítico, una "aureola de indianidad" (pp. 9295), catalogándolos finalmente como indianos y no como americanos, puesto que son, como mucho, mezcla de ambos mundos. Sin embargo, su razonamiento no careció de algunas contraindicaciones: pensemos en que, además de a Ercilla, Cueva o Ruiz de Alarcón, incluye en su lista, de manera harto optimista, a Lope de Vega o Calderón. La misma idea se hizo visible, por ejemplo, en la discusión sobre la mexicanidad de Ruiz de Alarcón protagonizada por Antonio Alatorre en aquellos mismos años (Urtiaga reseña brevemente la cuestión en la p. 97, n. 61 de su estudio). Nuestras críticas posmodernas vuelven sobre este tipo de exageración y parecen querer revivir el viejo debate sobre el americanismo de ciertos autores (véase Gaylord, 1996, p. 223).

27. La idea es ya antigua, puesto que ya la insinuó Jorge Albistur en un libro titulado Cervantes y la crónica de Indias de 1989.

28. Cf. Gaylord (1996, pp. 215, 217 y 223) y Wilson, que lo cita una porción de veces y durante muchas páginas seguidas (2003, passim). Y no es casualidad, ya que Beatriz Pastor juzgó ya en 1983 a Ercilla como un caso claro de "emergencia de una conciencia hispanoamericana" (cap. V).

29. Wilson en el capítulo 8 de su libro de 2003. 
$(1976, \text { p. 59) })^{30}$. En cambio, Gaylord, menos inclinada a los paralelos concretos, se limita a afirmar paladinamente que "Cervantes' masterpiece belongs as much to 'Latin American colonial' discourse as to Spain's Golden Age" en un artículo que no tiene desperdicio (1996a, p. 216).

Ambas autoras hacen un uso sesgado de las fuentes primarias áureas: más profuso la primera y muy escaso la segunda. Mientras Gaylord no cita más que alguna frase breve de Fernando de Herrera (1996a, p. 220), Wilson recurre en su libro de 2003 a un extraordinario elenco de obras y de autores, aunque éstos parezcan perfectamente ajenos a la cuestión americana, por lo menos a ojos de este modesto lector: su peregrino índice final de nombres propios abarca desde Apuleyo hasta Luis Zapata, pero no consigna prácticamente a ningún poeta, dramaturgo o prosista de los que en efecto se interesaron por las Indias Occidentales durante el Siglo de Oro.

En todo caso, el esfuerzo es vano a mi entender, puesto que el desinterés y el desvío de Cervantes hacia lo americano son más que evidentes, al menos en una medida que sólo admitiría un paliativo como el que apuntaba John H. Elliott en un artículo de 1976: es difícil estimar cuánta influencia puede o debe tener una realidad nueva en una sociedad tan lejana como ajena. Pero nuestras autoras no se arredran y han sido especialmente acuciosas a la hora de allegar o imaginar posibles argumentos a favor de lo que ellas llaman el Cervantes americanista. Lo curioso es constatar como, una y otra vez, recurren a las más esotéricas suposiciones, a las menos probables asociaciones para descubrir aquello que, de haber existido efectivamente, el alcalaíno hubiera sido el primero en sugerir en más de un pasaje de su vasta producción. Así, por caso, su interés y su conocimiento de la vida sevillana son palmarios y nadie podría negarlos; sucede igual con su dominio de la geografía peninsular, recorrida a uña de caballo y a lomo de mula, por no hablar de sus insistentes recuerdos italianos y africanos, etc. Con todo, según hemos analizado en sendos artículos de 2005, incluso el estrambótico Persiles se ha visto hoy interpretado en clave de presunto acertijo americano por nuestras estudiosas norteamericanas porque la veda parece estar abierta para cazar escritores y trasladarlos de un hemisferio al otro, en la dirección deseada por cada crítico posmoderno en función de sus particulares designios ideológicos. De ahí el extraño viaje o viraje cervantino hacia las costas americanas, porque, sorprendentemente, desoyendo al maestro Said y al mismo Cervantes, que clama en su desierto textual, los vientos de la modernidad hermenéutica no soplan hacia el este, sino hacia el -al menos para mí- más que improbable oeste. El hecho es que después de que Walter Mignolo acuñara el concepto gemelo de occidental-

30. Este último espejismo, muy extendido en ese continente y origen del nombre Latinoamérica, entre otras entelequias, puede proceder modernamente de las sutiles inferencias de gentes como José Enrique Rodó, Alfonso Reyes o José Antonio Ramos Sucre, entre otros, pero no es totalmente ajeno al ideario de nuestras estudiosas, que, a la zaga de Margaret Anne Doody, tratan a toda costa de pasar de contrabando la sugerencia de que existe un lejano vínculo entre la novela griega y lo americano. 
ismo, bien aprovechado por nuestras hermeneutas ${ }^{31}$, las interacciones se han vuelto supuestamente recíprocas.

En este punto, surge una nueva perplejidad para el historiador de la literatura de la época. Nuestras profesoras conceden más importancia a las escasas alusiones americanas de Cervantes que a su inequívoca y constante preocupación por los moriscos, el Imperio Turco, los piratas berberiscos, Argel o Jerusalén, asuntos indudablemente más urgentes en aquel tiempo ${ }^{32}$. En la literatura de la época y en sus obras, la ampliación geográfica del mundo novelesco bizantino se hizo más bien hacia oriente que hacia occidente, con la rara excepción del norteño Persiles. Por otro lado, las ideas cervantinas acerca de los turcos no son sustancialmente distintas de las de cualquiera de sus contemporáneos, incluyendo a un reaccionario Lope de Vega; su patriotismo juvenil no es, en efecto, distinto del lopiano o del del campeón nacionalista que después será Quevedo, que justamente se atreverá a mucho más que Cervantes en materia de defensa del indígena (frente a los invasores holandeses, no lo olvidemos, en su fantasía La hora de todos). Pero da la casualidad de que el polemista y espía Quevedo podía permitirse ir bastante más lejos en ese y en otros terrenos políticos que el mucho más prudente Cervantes o que Lope, que era dramaturgo y aspiraba a ser nombrado cronista real. El de Alcalá defendía que su rey atacase las costas africanas para acabar con la amenaza berberisca y no lo dudó a la hora de alistarse en la armada de Lepanto o de dedicarse a la ingrata tarea de recaudar pertrechos destinados a la Invencible. Sus piezas teatrales sobre el conflicto argelino resultan inequívocas y su actitud ambivalente hacia los gitanos, muy idealizados, no nos permite hacernos demasiadas ilusiones sobre su modernidad, ajena del todo a la nuestra. Acaso su discurso político más ponderado sea el que pronuncia el morisco Ricote en el Ingenioso hidalgo acerca de la expulsión de los de su raza (II, 54) ${ }^{33}$.

Frente a este panorama, a lo sumo nuestras hermeneutas mencionan al moro y al morisco como dos meros otros más (y perdónesenos la agramaticalidad, forzada a su vez por la sutileza de las cervantistas posmodernas), semejantes al gitano o al vizcaíno, es decir, una minucia textual, un caso paralelo y marginal, aunque aquéllos constituyan el eje de una parte no pequeña de la producción

31. Véase especialmente Wilson (2003, p. 7).

32. Con la honrosa excepción de Fuchs, quien, en su libro Mímesis and Empire (2001), trató ambas coordenadas con parecido énfasis. En todo caso, un repaso del Vocabulario de Cervantes de Carlos Fernández Gómez basta para poner las cosas en su sitio. Veamos las ocurrencias de los siguientes términos en la producción cervantina: turco (13 veces), turquesco (9), árabe (1), arábigo (6) e italiano (8), frente a India (1), indio (2), indianazo (1), indiano (2), mejicano (1), Potosí (2) y el neologismo potosisco (1), por no hablar del volumen o la importancia relativa de los personajes indianos frente a la de otros.

33. Por ello cabe afirmar, como ha hecho $\mathrm{M}^{\mathrm{a}}$ Soledad Carrasco Urgoiti, que se trata de "una cuestión sociopolítica de gran envergadura que preocupa al autor, pues también la recreará en el Persiles" (Quijote, ed. cit., II, p. 204). Nada remotamente parecido podría asentarse sobre sus presuntas veleidades americanistas. 
cervantina $^{34}$. Esta paradoja -conjeturo- podría deberse probablemente a varias razones: el semita ofrece relativamente menos exotismo en una época multicultural como la nuestra, de casi obligada multipolaridad geográfica; tampoco resulta tan atractivo para una incursión de la crítica literaria en un mundo como el de hoy ${ }^{35}$; es un caso más natural y fácilmente presumible, y por lo tanto no autoriza los audaces vuelos de la imaginación alegórica que se le presuponen al crítico literario actual; Américo Castro ya desbrozó en parte ese terreno semítico en un anticipo de nuestras lecturas actuales, por lo que el asunto no permite un oportuno lucimiento bibliográfico, especialmente arduo en un terreno como el Siglo de Oro, donde en apariencia casi todo se ha escrito $\mathrm{ya}^{36}$.

En nueva contradicción, descubrimos que el enaltecimiento de lo americano-cervantino tampoco conlleva un verdadero rescate del indígena amerindio en las obras de Cervantes, posiblemente porque sus apariciones son tan notablemente escasas, que, aunque alguna de nuestras estudiosas haya hecho esfuerzos en esa dirección, casi tira en ese punto la toalla antes del combate ${ }^{37}$. Y la crítica menos prejuiciosa ha confirmado hasta la saciedad esta idea de la casi ausencia del indígena en la literatura de la época y en Cervantes $^{38}$.

34. Compárese esta aporía crítica con el equilibrado acercamiento del citado Castillo al problema del amerindio en el teatro áureo, asunto que él compara muy oportunamente con la visión del moro o del judío (en sus pp. 44-45, por ejemplo). Para el presunto arabismo cervantino, que también es tema polémico, véase Claudio Sánchez Albornoz (1962, I, p. 586).

35. El hoy de estas líneas es fundamentalmente el de los años 2009-10 en que las redacté por primera vez, y no el de enero de 2011, cuando la revolución egipcia y de otros países árabes ha cambiado la perspectiva e introducido nuevas expectativas, finalmente defraudadas en el otoño de 2012 en que cierro estas páginas. Por lo demás, en este punto Said fue un afortunado francotirador o una golondrina que no hizo verano.

36. La común afirmación de que todo está escrito no es estrictamente cierta ni siquiera en el caso de Cervantes: recientemente he repasado la bibliografía relativa al nombre de don Quijote, una cuestión de base para el entendimiento del libro, y he hallado lagunas en ella; desconocemos aún la cronología cierta de muchas obras cervantinas y estamos trabajando todavía algunos en el terreno de las obras atribuidas o perdidas. ¿No es preferible entregarse a tareas de ese tipo que especular, en el resbaladizo éter de las más vagas y caducas ideologías, sobre lo divino y lo humano en el Quijote, como si estuviéramos en 1890 y no en 2012 ?

37. Siendo justos, Wilson, en su obra magna sobre el asunto, los menciona como inexistentes en un pasaje cervantino, casi invocados en rebeldía (2003, p. 23); aparecen más en serio en la p. 86; surgen en una crónica de Indias sin relación con Cervantes en la p. 127; son invocados a propósito de los programas utópicos del XVI, de nuevo ajenos a ese novelista (pp. 144-145); y, por último, salen a colación de La Araucana (pp. 164-165). Esto es, hablando en plata: el mejor estudio de nuestras autoras sobre la influencia ultramarina en Cervantes confirma a las claras que los indígenas americanos no comparecen prácticamente en las obras cervantinas y que Wilson sólo ha podido aludir a ellos incidentalmente.

38. Cf. Morínigo (1946, pp. 119 y 149), Urtiaga (1965) -que sólo alude a los indígenas en cuatro páginas de su libro-, el tomo colectivo La imagen del indio (1990, p. 153), mi propio volumen cervantino de 2006 (p. 237) y el estudio reciente y ya aludido de Castillo, aunque éste se ciña a trece comedias especializadas de varios ingenios. $C f$. también una breve mención negativa en Daisy Rípodas Ardanaz (1991, p. lxvii), en un "Estudio preliminar" en el que, por lo demás, no hay ningún apartado dedicado al aborigen, algo revelador en una historiadora tan notable. Y, si se me perdona la autocita, también escribía yo premonitoriamente hace más de una década: "Podemos afirmar que los indígenas americanos, tan problemáticos para los teólogos, juristas e intelectuales moralistas del tiempo, no gozaron del favor de los escritores de la prosa áurea; o, al menos, no en la medida que 
En suma: encarados con el texto literario que se pretende estudiar, aparentemente falla la más elemental premisa posmoderna de defender al olvidado y al marginado históricos. La obra cervantina no autoriza a escala humana, en resumidas cuentas, el afán descentralizador y reivindicativo del crítico a la moda, que se ve obligado a transitar caminos mucho menos frecuentados.

Hemos hablado de consignas, ¿pero cuáles son éstas? Uno de los problemas centrales planteados implícitamente por este grupo es el de la identidad americana, que se ha venido debatiendo durante más de un siglo, por lo menos desde el relevante Ariel del uruguayo José Enrique Rodó $(1900)^{39}$ o las disquisiciones de Ricardo Rojas acerca de lo que llamaba el "abolengo de los argentinos" (1912), hasta las obras fundamentales de Tzvetan Todorov, La conquête de l'Amérique, la question de l'autre (1982), Sander L. Gilman, Difference and Pathology: Stereotypes of Sexuality, Race and Madness (1985) y Michel de Certeau, Heterologies: Discourse on the Other (1986), entre otros. Según era de esperar, Barbara Fuchs ha puesto en relación este asunto de la identidad con Cervantes en un estudio de $2003^{40}$. Y asimismo, a la zaga de esas corrientes críticas, una cervantista como Wilson ha podido proponer, sustentándose en Mariscal, que la obra de Cervantes es una producción mestiza ${ }^{41}$, algo que, después de todo, no debe de extrañarnos en hispanistas que proceden en muchos casos del análisis del discurso colonial.

Todo esto tiene algo de paradójico, puesto que supone, de nuevo, dos esfuerzos un tanto contradictorios: fomentar el sentido de la identidad hispanoamericana y a la vez difuminar esa identidad en una suerte de vasto magma multicultural de mestizaje e hibridismo que abraza todo, desde el Mediterráneo hasta el Pacífico, y que, sorprendentemente, incluye en su nómina al manchego y cordobés Miguel de Cervantes. Por esta senda circulaba ya hace unos años el ambicioso volumen de Margaret Anne Doody, titulado nada menos que The True Story of the Novel (1996), donde su autora insistía

cabría esperar dentro del orden de prioridades que impera en nuestros tiempos y que se aplica un tanto anacrónicamente a los autores clásicos" (1999, p. 243).

39. Resulta aquí interesante la consulta de la entrada arielismo del Diccionario enciclopédico de las letras de América Latina.

40. Y también Gaylord, supuestamente, en un trabajo titulado "Getting to Honduras: Allegorical Geographies and American Otherness in Las seiscientas apotegmas of Juan Rufo", que debería haber aparecido, según ella, en el libro colectivo de editado por ella, Luis Girón-Negrón y Ángel SáenzBadillos, 'Los quilates de su oriente'. La pluralidad de culturas en la Península Ibérica en la Edad Media y los albores de la modernidad (Real Colegio Complutense, Harvard University, 17-18 January, 2003). Estudios ofrecidos a Francisco Márquez Villanueva, Newark, Delaware, Juan de la Cuesta (¿en prensa?), que no he logrado localizar.

41. Exactamente en su Cervantes, the Novel..., p. 106, y también en su artículo de 1998 (p. 59). Cf. Mariscal, "The Crisis of Hispanism as Apocalyptic Myth". La misma idea aparecía en Gaylord, 1996b, donde esa autora debatía el impacto y la significación del Quijote en la enseñanza, como parte de un canon nacional, y defendía una fusión de hispanistas y no hispanistas, así como la supresión de las fronteras entre siglodeoristas y colonialistas en la unidad superior de la lengua española. Al margen, diré que esa frontera no lo ha sido tanto, por ejemplo, para un estudioso y cervantista como el recientemente fallecido Juan Bautista Avalle-Arce, que ha dedicado sus esfuerzos a ambos campos sin mayor inconveniente. 
repetidamente en la idea de que el género novela está relacionado con orillas, ríos -y citaba una lista de ejemplos entre los que figuraba el fluvial Lazarillo de Tormes-, lagos, playas, mares, costas o pantanos (p. 321) ${ }^{42}$; en que la novela es siempre, forzosamente, "a mongrel mixture" (p. 483) ${ }^{43}$, y en que

The history of the Novel is never pure. The stories told by the Novel are not "pure". They are stories of mixture and variety, of boundary-crossing and changing. The Novel itself is not "pure" and refuses ever to pretend to be so. It rejoices in a muddy messiness that is the ultimate despair of Fascismus. No kind of literature has ever said more fully or firmly that there is life before death. The Goddess in her own realm is unconquerable. We make a not unimportant spiritual and political as well a personal move when we open a novel and become initiates, entering upon the marshly margins of becoming (p. 485) 44 .

Esta noción telúrica, acuosa, romántica, posmoderna (y, de paso, pintorescamente antifascista) puede resultar fecunda y evocadora, pero es también un tanto inasible y roza el misticismo, un misticismo que no beneficia a un asunto a mi modo de ver tan concreto como es el de la relación de Cervantes con lo americano o lo indiano, y probablemente tampoco a la historia concreta de la novela española u occidental ${ }^{45}$.

Por lo demás, siguiendo a Doody, Wilson ha planteado un interesante problema en lo que se refiere a la idea de la novela como un género nacido en la periferia de un imperio (1999b, p. 59). El argumento original de que el género novela y la novela griega en concreto tuvieron que surgir necesariamente en el fértil humus de una civilización políglota y multicultural o de un imperio multilingüe no parece demasiado sólido, en especial si consideramos que los romanos, el pueblo que dominaba el mediterráneo contemporáneo, en franca negación del universalismo, no aparecen como tales en las principales

42. Sería prolijo estudiar tantas geografías novelescas como han existido, pero, en el caso de los primeros pasos del género en Grecia, no hay duda de que estamos ante una geografía muy ligada al mar, las islas y las costas, y esto por la sencilla razón de que ese entorno era esencial en la vida de los griegos: $c f$., aunque no trate específicamente el tema geográfico, M. Brioso Sánchez (2002), con amplia bibliografía.

43. La noción de la novela como monstruo indescriptible es ya vieja: pensemos en la definición cortazariana de ese género proteico como una "cosa impura" y como "el monstruo de muchas patas y muchos ojos" (2001, p. 109).

44. Comp. Gaylord, que hablaba en el mismo año de la noción novedosa de bridge-crossing para describir sus construcciones intergenéricas y transatlánticas ("The True History...", p. 225).

45. En este punto como en otros, el voluntarioso optimismo de Gaylord o Doody contrasta con el pragmatismo de Wilson, que hila mucho más fino, pues, luego de proclamar su entusiasmo por el tomo de Doody de 1996, se limita a rodear la novela cervantina con un halo de vaporosa delicuescencia posmoderna: "Aiming, instead, for a transcultural theory, I shall suggest that the novel is a wildly mixed genre that rises - whether with Heliodorus or Cervantes or Defoe- from the hybrid soil of multilingual empires" (2003, p. 44). Para ser francos, es más difícil discrepar de una idea que, aunque poco justificada, se afirma con semejante delicadeza. Por otro lado, no vendría mal en este punto un repaso de la muy exhaustiva y original Historia de la novela en España de Juan I. Ferreras, de reciente aparición. 
obras conservadas de ese corpus antiguo y si pensamos que el poliglotismo de autores como Heliodoro es un mero artificio tardío que apenas pretende conferir verosimilitud espacial o territorial a sus relatos ${ }^{46}$.

En puridad, la misma invocación de los escritos de Mijail Bajtín resulta periférica en sí, amén de contradictoria, puesto que este estudioso ruso, aun a pesar de establecer relaciones entre la novela griega antigua y la moderna, hace hincapié en particular en que aquélla, como estructura fuertemente abstracta y esquemática de un argumento de amor y aventuras, puede incidir y de hecho incide sobre todo en géneros medievales, renacentistas y barrocos, pero por sus rasgos está muy distanciada de la narrativa propiamente moder$\mathrm{na}^{47}$. Por tanto, Wilson, Gaylord o Doody no las tienen todas consigo cuando consideran la novela griega como un precedente firme de la novela moderna y del novelar cervantino. Por lo demás, Cervantes no toma como referencia la novela griega, sino el caso único de Las Etiópicas de Heliodoro, que es la novela antigua que conoce, y Bajtín tampoco empleaba la noción de hibridación en el mismo sentido -varios, en realidad- que hoy sugiere Wilson (1999b, pp. 52-54).

La idea de fondo de un Cervantes americano reviste cierto interés, pero no se sustenta sobre una base firme y, desde luego, tampoco parece aplicable a las obras cervantinas con la insistencia que ponen Wilson o Gaylord. $\mathrm{Su}$ intuición es brillante, pero tampoco parece demostrable, particularmente si tenemos en cuenta que la novela cervantina supuestamente pionera en el género para Wilson y compañía, no nace en Ultramar, sino que puede aludir más o menos ocasionalmente a esos territorios. Esta corazonada de nuestras cervantistas es lo que explica, aunque no justifica, su afán de traducir todos los elementos posibles de la narrativa de Cervantes en términos indianos pretendidamente encubiertos, de suerte que pueda considerársela como una producción americana, de un modo u otro. No deja de ser, sin embargo, una argumentación muy cogida con alfileres, pues en realidad estas autoras nunca han podido demostrar que el género haya surgido modernamente en las Indias Occidentales, sino que se ven obligadas a admitir lo que ya sabíamos, esto es, que se originó en Europa. Como mucho, se trataría de occidentalizar la cultura española que contribuyó a alumbrar el género, como si el contacto con Ultramar después de 1492 hubiese fecundado la prosa española y dado lugar al gozoso nacimiento de la novela moderna, algo que nuestras críticas parecen sugerir pero que es evidentemente muy difícil de probar. Y, si esto falla, siempre queda el recurso de echar mano del mejor novelista conocido, Miguel de Cervantes Saavedra, para tratar de forzarlo a abordar atolondrada-

46. Véanse nuestros trabajos de 2002 y 2003, donde hemos tratado de demostrar que Cervantes pudo haber imitado en el Persiles el tratamiento del poliglotismo de Heliodoro.

47. Véase el análisis expuesto en el ensayo que en la versión española (manifiestamente mejorable) forma parte del volumen Teoría y estética de la novela (1989, pp. 239-263). Ahí se conjugan observaciones muy atinadas con errores graves, como las escasamente señaladas distinciones entre las novelas griegas conservadas completas, como si no estuviesen sujetas a una fuerte evolución. 
mente el tren de un género que ya está en marcha e imaginarlo pertrechado de un dudoso equipaje americano.

Otra vía, sumamente eficaz, para apoyar semejante tesis es asociar sugestivamente la recuperación de la antigüedad en el Renacimiento con la expansión geográfica renacentista, emparejando tiempo y espacio. Esta asociación de Wilson le dará pie después para cimentar otras conexiones harto menos probables de Cervantes con el Descubrimiento, con las crónicas americanas, de la novela como género con Occidente, etc. ${ }^{48}$.

Volviendo a la cuestión principal, hay que pensar, sin embargo, que la defensa de lo telúrico y lo original americano parece haber exigido tradicionalmente, en maniqueo razonamiento, el menosprecio o el rechazo de toda influencia española positiva. Ya subrayó Tovar ese punto en 1970 y 1981, cuando deslindó dos tipos de críticos desvalorizadores de lo que él llamaba la "obra [cultural] de España en América": por un lado, "los historiadores de tendencia moderna y liberal [que] encuentran que el viejo mundo español de América se basaba en el clero y era "un rebaño ignorante y supersticioso"; $\mathrm{y}$, por otro, "ciertos sabios actuales, que lo ven todo desde la antropología, como si estuvieran en el cielo de las estrellas fijas, [y que] oponen, hablando de indios norteamericanos, la feliz y bienaventurada 'aculturación' actual a los primeros contactos que ocurrieron con 'los pillastres' (rascals) que llegaban cabalgando desde Nueva España” (1970, p. 51). No hará falta insistir en que la segunda especie se corresponde bien con la tendencia buen-salvajista de Levi-Strauss. Pues bien: nuestras cervantistas no pertenecen del todo a ninguna de las dos corrientes, pero acaso desean hacerse pasar por cualquiera de ellas cuando, por ejemplo, sacan a colación por igual al Inca Garcilaso -del que también se ocupaba ceñida y justamente Tovar (p. 25) - y al Subcomandante $\operatorname{Marcos}^{49}$. En realidad, se encuentran en una incómoda posición de mestizas ideológicas ellas mismas, puesto que defienden la cultura occidental que representa un Cervantes, pero intentan también americanizarla y hasta indigenizarla en lo posible, suponiendo, por ejemplo, que ese novelista conoció al Inca en Montilla ${ }^{50}$. En este caso lo que pretende vigorizarse -desde Norteamérica, en otra curiosa paradoja- es la identidad no siempre segura de

48. Wilson, Cervantes, the Novel..., pp. 18, 21, etc.

49. La pintoresca sección VII de la bibliografía de Correa Díaz se ocupa precisamente de los que él llama "Personajes históricos americanos en su dimensión quijotesca", es decir, entre otros, el citado Marcos, Simón Bolívar, Cantinflas, Fidel Castro, Hugo Chávez, Ernesto Ché Guevara o Compay Segundo (pp. 78-80). Como puede observarse, mestizos o criollos, blancos o negros, estos personajes nos hablan de la pretensión americanizadora, bien que algo superficial o trivial, de Correa. El esfuerzo de Wilson es mucho más sutil, a la par que más anglófilo, puesto que, a través de complejas asociaciones, vincula a Cervantes con el Inca, Coleridge, Defoe, Borges o Carpentier, entre otros (repase el lector el índice de nombres propios de su libro de 2003).

50. Véanse las páginas 191-193 del estudio de Wilson Cervantes, the Novel... Sobre el problema del mestizaje, central en la cuestión de la identidad de la América del Sur, la bibliografía es inmensa, aunque no lo es tanto ni mucho menos el caudal de los estudios sobre el valor de lo racial e identitario en la visión historiográfica. Basten aquí sobre este último problema las consideraciones de Tovar (1970, p. 19) y en general los ensayos de mi colega Juaristi ya citados y centrados en la precaria y tosca edificación del moderno nacionalismo vasco. 
América Latina, y se trata de hacerlo a costa de Cervantes, que de nada tiene culpa en este entuerto político moderno ${ }^{51}$.

Sobre este punto, no se me alcanza qué aspectos de su producción avalan una posible mezcla o hibridación y en especial un mestizaje americano; y, en segundo lugar, qué de valioso podría aportar ese famoso mestizaje, suponiendo que en efecto se produjera, a la interpretación de los textos de Cervantes. De haber existido tal cosa, parece claro que debería ser un mixto con lo árabe y lo oriental o un muy matizado orientalismo, como a menudo se ha observado y según podría parecer plausible, desde las primeras obras teatrales cervantinas, entre otras la juvenil El trato de Argel, la pieza atribuida La conquista de Jerusalén, Los baños de Argel o La gran sultana, por no hablar de las novelas ${ }^{52}$. Nada me hará dudar de que este visible orientalismo es un factor esencial, aunque complejo, y de que el alternativo occidentalismo resulta ser poco más que un residuo o poso natural en cualquier español bien informado de la época, que, como era moneda corriente entonces, habría hecho pocos esfuerzos para estar al día en materias indianas ${ }^{53}$, aunque se hubiese ilusionado momentáneamente, durante unos meses de su vida, con un posible destino burocrático en las Indias. Y esta ilusión, por más partido que se le pretenda sacar en estos tiempos de acendrado multiculturalismo, ya que no cabe considerarla un accidente o una casualidad, sí puede interpretarse a la inversa de como lo hacen nuestras estudiosas, en calidad de síntoma de lo contrario que ellas pretenden inferir: si Cervantes tanto se entusiasmó con lo americano, hasta el punto de proyectar un viaje hacia Occidente, ¿por qué entonces fueron tan parcas y tan ambiguas sus alusiones a Ultramar? ¿No será porque su interés fue meramente circunstancial, puesto que, como la mayoría de sus contemporáneos, sólo albergaba en su imaginación asociaciones monetarias y triviales con las Indias Occidentales y no una verdadera curiosidad intelectual?

Pero henos aquí de nuevo en plena cuestión conceptual del otro, en este caso del otro americano, a mi entender muy poco visible en la producción cervantina. Wilson cita varios ejemplos de otredades cervantinas: gitanos, vascos y moriscos ${ }^{54}$-después añade a florentinos, franceses, peregrinos alemanes, calabreses y moros (1999b, p. 55)-; y sin duda algunas de ellas, si no todas, resultan más convincentes y de más peso como influencias positivas y concretas en nuestro escritor que la alegada presencia de lo americano en sus páginas. Esa misma investigadora procura difuminar este problema en un

51. Acerca del embeleco de la identidad puede verse el inteligente artículo de José Luis Pardo titulado expresivamente "El conocimiento líquido. En torno a la reforma de las universidades públicas" (2008), donde su autor define la identidad posmoderna como "esa forma nueva $-\mathrm{y}$ sin embargo tan antigua- de pobreza que caracteriza la penuria de nuestras sociedades avanzadas y prósperas". Y no es casualidad que estos trasiegos identitarios abunden precisamente en las facultades de humanidades de las universidades anglosajonas, que se han situado en la vanguardia de esta nueva escolástica líquida y difusa.

52. Sin embargo, véase Bataillon (1966, p. 796) y Sánchez Albornoz (1962, I, p. 586).

53. Cf. Bataillon (1966, p. 817), Castillo (2009, pp. 14 y 265-266) y Eisenberg (2002, passim).

54. 1999 b, p. 53, y 2003, p. 85. 
párrafo y página en los que junta a todos los otros posibles en la producción de Cervantes, sin lograrlo del todo, a pesar de apoyarse en la novela griega, en Bajtín y en Mignolo (1999b, p. 53). Incluso basa su argumentación en que se trata en todos los casos de periferias del Imperio o del mundo moderno de entonces, aunque tampoco creo que pueda considerarse tal cosa a los gitanos, siempre incrustados en la Península, bien que mal integrados y difícilmente periféricos, o a los italianos.

La transculturación es, en sí, un concepto de difícil aplicación y objetivación, que parece confundir más que aclarar las cosas aquí, por más que Wilson y Gaylord insistan en sacarla a colación a menudo, como la primera hace en esas mismas páginas recurriendo a ejemplos y autoridades posmodernas, hindúes o latinoamericanas (1999b, p. 52), que de poco ayudan en el caso que nos ocupa. Podemos deducir, al menos en lo que nos concierne, que esa transculturación es una necesidad del crítico de turno, más que una realidad que emane de los textos analizados.

Más astutamente, unas páginas más adelante de ese mismo artículo de 1999b (pp. 55-56), volvía Wilson a la carga con un argumento menos endeble -o más difícilmente refutable, por elusivo- que los precedentes: lo híbrido sería en el Quijote el esquema de los narradores interpuestos y bilingües de esa novela: el autor arábigo Cide Hamete Benengeli y el morisco aljamiado que funge como traductor improvisado ya en I, 9, después del episodio del vizcaíno -otro otro idiomático del que nuestra cervantista se olvida, quizás por el humorismo disolvente del pasaje en el que comparece (I, 8)-. Pero se me antoja que comparar estas bromas autoriales cervantinas del primer Quijote con el (discutible) poliglotismo de la novela griega, como ahí hace Wilson (1999b, p. 55), está un tanto fuera de lugar. Y, en todo caso, nada de esto tiene que ver con el asunto americano que nuestra investigadora desliza de tapadillo a colación de estas cuestiones, poco después, en la página 56 de ese mismo artículo, a menos que verdaderamente se quiera sacar de contexto a ese vizcaíno, que acompaña a su señora a Sevilla, desde donde ella partirá a América con su marido (p. 99). Sorprende, por otra parte, que Wilson no haya aducido el Persiles cuando trataba el poliglotismo de las antiguas novelas griegas -sobre todo, la de Heliodoro-, que algo se le parecen en ese punto, y sí lo saque a relucir cuando necesita a toda costa un nexo que vincule de alguna forma su teoría post-bajtiniana del hibridismo novelesco con alguna obra cervantina: de ese modo puede encarar al último Cervantes con lo americano, prácticamente ausente del Quijote, aunque éste le parezca a ella un semillero de híbridos interlingüísticos. Es decir, que, cuando conviene, se apoya en el Ingenioso hidalgo para probar una parte de su argumento, y cuando éste se agota en sus virtualidades híbridas, echa mano de la Historia setentrional a falta de mejor solución, y de ahí la inconexa redacción de las páginas 56-57 de su artículo citado, en las que salta nerviosamente y sin demasiado orden de unas cuestiones a otras y de un ejemplo a otro.

En esa misma dirección, esa estudiosa proclama el poliglotismo quijotesco y supone que el Quijote "rises from these polyglot energies and positions itself 
on the border between multiple cultures and languages" (1999b, p. 54); pero, en realidad, una novela o protonovela como La lozana andaluza y algunas piezas teatrales del mismo Cervantes son bastante más políglotas que esa novela manchega, según mi entender. Y justamente la obra de Delicado no es tenida en cuenta ni citada ni por Doody ni por Wilson en sus trabajos respectivos, a pesar de que la primera autora sí mencionara en una ocasión la Tragicomedia de Rojas, claro antecedente de La Lozana, entendida como una novela (1996, p. 233). Seguramente es porque la obra delicadiana no ofrece el menor asomo occidentalista - su vocación es inequívocamente mediterránea- y sin embargo es un perfecto experimento de multiculturalismo y de creatividad en libertad en su doble condición de prodigioso retrato del natural o de portentosa novela dialogada, según se quiera. Y el caso Alemán queda también al margen puesto que, de nuevo, es obra de equivocada vocación peninsular e italianista y no especialmente inclinada al poliglotismo. De modo que, al faltarle a ciertas obras algunos ingredientes que nuestras estudiosas consideran indispensables en la novela, éstas ya no son tenidas en cuenta. Comprobamos, así pues, cómo la presunta tesis innovadora, la sonora campanada crítica de nuestras cervantistas, no sólo impide leer razonablemente a Cervantes, sino que distorsiona el panorama del género que ellas se proponen iluminar y margina a algunos de sus cultivadores más ilustres, como Delicado o Alemán, un Alemán que precisamente, a pesar de haber muerto en México, tampoco reúne las condiciones del poliglotismo ni la periferia transcultural, tan exaltadas por esta nueva escuela de cervantismo.

En este punto, podemos recapitular: ni la esquinada Celestina ni la no menos conflictiva Lozana andaluza ni el Lazarillo de Tormes -según buena parte de la crítica, la primera novela moderna, por lo menos en España- son novelas para Wilson $^{55}$, dado que ni las cita ni contienen, al parecer, los ingredientes magistrales que hacen que un texto pertenezca por derecho propio a ese género, puesto que, como mínimo, tanto la primera como la última son ajenas al principio de haber nacido "at a boundary line between languages and cultures" (1999b, p. 59), y la segunda, alumbrada en la Italia de los novellieri y del Aretino, verdadero colmo del pidgin mediterráneo, es dialogada, medio italiana o simplemente marginal respecto al paraíso novelístico occidentalista preconizado por Wilson. Con todo, se entiende perfectamente que esa investigadora haya orillado esos tres ejemplos, dado que la pieza de Rojas (o de quien sea) sólo ofrece los dos conflictivos registros sociolingüísticos que son de sobra conocidos y sus múltiples meandros paródicos; dado que -y esto no deja de sorprenderme- el Retrato de Delicado permanece, según se deduce de nuestro recorrido por los ensayos de esta nueva crítica cervantina, en el limbo de los extramuros de la novela, a pesar de su enorme ductilidad en el campo de los idiomas, los dialec- 
tos, las hablas y las linguas francas ${ }^{56}$, y por tanto de lo que, según presumo, es la base de la transculturación; y dado que la picaresca anónima pionera no es multilingüística ni pone énfasis en híbridos algunos, puesto que todo en ella es neto e hirientemente peninsular. En extraña paradoja, comprensible al fin por la alta especialización de nuestras cervantistas, la obra que mejor encajaría con el planteamiento de la novela como constructo multilingüe queda, así, fuera de la cuestión ${ }^{57}$. Pero, en realidad, entiendo que la razón más evidente de nuestra autora para pasar de puntillas junto a esas tres piezas literarias cruciales es que ninguna de ellas contiene siquiera remotamente ingredientes americanos de importancia, lo que las vuelve inservibles para sus designios, a pesar de haberse publicado todas después de 1492 y sabiendo que Delicado dedicó un tratadito al llamado leño de Indias. Y quizá haya que sospechar, por último, que nuestro grupo de neocervantistas no es totalmente ajeno a lo que podríamos llamar el cervanto-centrismo del ubicuo pero miope Harold Bloom, incapaz a su vez de reconocer la importancia de La Celestina o de la novela picaresca anterior al Quijote $^{58}$.

Si repasamos el trabajo citado de Jameson, encontraremos que su temprana intuición de la literatura del Tercer Mundo -así lo llamaba él en ese entonces- como una literatura alegórica nos pone sobre la buena pista. Es más que probable que nuestras investigadoras estén haciendo, consciente o inconscientemente, una interpretación de las obras cervantinas en clave de alegoría. En realidad, han elaborado una geografía alternativa del Quijote, las Novelas ejemplares o el Persiles, una espacialidad imaginaria en la medida en que no responde ni a la escritura cervantina ni a sus referentes y modelos más visibles. Y el propósito de tal maniobra, igual que en los ejemplos analizados por Jameson hace un cuarto de siglo, sólo puede ser alegórico y, por tanto, ideológico. p. 56).

56. Aunque precisamente Wilson insiste en el valor de la lengua franca en el Quijote (1999b,

57. Y, en no menor paradoja, Wilson salta enseguida del Persiles al Robinson Crusoe de Defoe, cuya pertinencia me parece escasa en este punto, a pesar de la insistencia de esa cervantista (véanse 1999b, p. 57; y 2003, cap. 3 y passim). Incluso llega a afirmar que, cuando se lee esa novela de Defoe "no cervantista can forget that the first part of the Persiles similarly begins with an arduous escape from Barbary, from an Americanized 'Barbaric Isle' whose inhabitants are also cannibals" (1999b, p. 58); o escribe que "The shipwrecked protagonists of both the Persiles and Robinson Crusoe, in short, are clearly responding to the spatial and allegorical presence of Spain's empire in the Indies" (p. 59). Curiosamente, no se acuerda de Moll Flanders, del mismo Defoe, que tiene un interesante episodio americano, pero quizás esa omisión se debe a que la misma Moll echa por tierra con sus palabras cualquier posible pretensión de reducirla a la condición de americanista: "I (...) did not know what the word geographical signified, had only a general knowledge from long conversation with people that came from or went to several places (...)" (p. 359); aparte de describir sencilla y eficazmente el escaso conocimiento que, por lo general, tenían de América muchas personas del XVIII (y del XVII), en Inglaterra (o en España).

58. Medite el lector acerca del siguiente enigma: Bloom confina la obra de Rojas y el Lazarillo al limbo de su lista de lectura final (p. 543), pero nos conmina a leer a Samuel Beckett y Emily Dickinson como eminencias universales; nuestras cervantistas, que a buen seguro creen estar en las antípodas ideológicas de Bloom, caen en la misma extraña contradicción a pesar de que están tratando de defender una chocante centralidad americana de Cervantes. 
¿Alegorías a estas alturas del siglo XXI? Sí, si contribuyen a un fin programático. El rendimiento político de un Cervantes americano o americanizado en algún grado no sólo está hoy a la vista, sino que además fue descubierto por los autores de las continuaciones americanas del Ingenioso hidalgo en el XIX y por José Toribio Medina y sus epígonos en el siglo XX, incluyendo a Irving Leonard, Emilio Carilla y Raúl Porras Barrenechea, que elucubró, por ejemplo, que el Caballero de la Triste Figura pudo ser una sátira de los conquistadores de Indias (1955, p. 238 $)^{59}$. Y precisamente Medina había sido el primero en hablar de un Cervantes americanista en 1915.

Pensemos en las visiones alegóricas del espacio, sacralizadas o devocionales, del Barroco, estudiadas recientemente por Françoise Delpech y sus colaboradores, donde el paisaje aparece codificado y traducido en forma de altas metáforas y abstracciones ${ }^{60}$. ¿No es también cierto de nuestras estudiosas que crean con sus espacios cervantinos americanizados unas "invenciones y mixtificaciones [que] se nos aparecen de este modo como artefactos ideológicos tendentes a una remodelación del territorio por medio de un imaginario histórico nada inocente"? ${ }^{61}$. Mutatis mutandis, se trata de la misma cosa: donde leemos territorio, basta poner territorio literario, y donde dice histórico, escribiremos perfectamente historiográfico. Estas investigadoras, en la creencia de que descubren un nuevo continente que sólo existe en la imaginación, pueblan los textos cervantinos de "mitos y sacralidad", en palabras de Fernando Martínez Gil ${ }^{62}$, aquí mitos y sacralidad americanos, indianos, ultramarinos. Ese aparato de mitos, a la vez que pretende remodelar el espacio literario, reescribe el territorio crítico. Y lo que era una artimaña barroca para promocionar ciudades o lugares - las consabidas Sevilla o Zaragoza como nuevas Romas, por ejemplo- es ahora un truco para promover unos estudios de americanismo al socaire de necesidades políticas sobrevenidas en plena posmodernidad, o incluso una añagaza para suscitar congresos y encuentros especializados, o convocatorias de plazas para presuntos expertos en lo que simplemente no existe fuera del discurso crítico ${ }^{63}$.

Nuestras estudiosas no sólo han sembrado al viento una porción de suposiciones peregrinas, sino que además han pretendido corroborar esas imaginaciones con el concurso de la novela griega, de las crónicas de Indias, de Ercilla, del Inca Garcilaso, de Daniel Defoe, de Samuel Taylor Coleridge, de Borges, de Bolívar y hasta de la más clásica historiografía española, puesto

59. Baste ver el catálogo de despropósitos y exageraciones festivas reunido por Wilson, que incluye nombres como los del citado Porras, Germán Arciniegas, Manuel Durán, Daniel P. Testa, Pedro Acosta o James D. Fernández, entre otros (1999b, pp. 39-41).

60. Me refiero a la importante obra colectiva L'imaginaire du territoire en Espagne et au Portugal (XVIe-XVIIe siècles), de 2009. Precisamente en ella se trata la geografía del Persiles y de las Ejemplares.

61. Tomo la cita de la reseña de la obra de Delpech preparada por Fernando Martínez Gil, p. 13.

62. En un artículo titulado muy expresivamente "La realidad histórica de una geografía imaginaria”, p. 13.

63. Correa, por ejemplo, propone la creación de "un campo de estudios en formación" para estas cuestiones (2006, p. 12). 
que, por ejemplo, Gaylord ha atribuido nada menos que a Menéndez y Pelayo y a Américo Castro el inicio del "decentering of focus" que ha dado pie a sus propias tesis americanistas (1996, p. 223), cuando en realidad ese descentramiento obedece más bien a la moderna labor de zapa del post-estructuralismo francés y el revisionismo identitario latinoamericano de los años 70 del siglo XX.

En verdad, el problema es antiguo, como mínimo tanto como el célebre libro de Said titulado Orientalism, obra fundadora de la teoría postcolonial en 1978. Jameson consideró algo después ese orientalismo justamente como una "strategy of otherness" y de apropiación cultural de la modernidad ( $p$. 77). Aquí la cuestión es doble y conviene deslindarla: si Said entendía que el Oriente había sido objeto de una apropiación cultural por las potencias occidentales, también la cultura de esas potencias iba a ser, andando el tiempo, objeto de otra apropiación simbólica por la crítica del palestino Said y, en especial, de sus discípulos de hoy día ${ }^{64}$. Sin embargo, se prefiere al Cervantes americanista frente al Cervantes orientalista, evidentemente porque éste último no ofrece como objeto de estudio un rendimiento identitario americano y neocolonial. En el caso que nos ocupa tiene lugar una apropiación como la que sugirió Said y con parecidos objetivos: se da la vuelta a la moneda del imperialismo con intenciones revisionistas, de presunta justicia histórica. $\mathrm{Y}$ asistimos a un nuevo colonialismo cultural inverso, aunque ahora con la excusa del bienpensante humanismo y del progresismo abarcador que denunciara Jameson en su día. El colonizado es Cervantes y su obra el objeto de esa colonización intelectual. De ahí que importe poco lo que en sus novelas y comedias se anote acerca de las Indias Occidentales, puesto que lo que cuenta es el valor de cambio ideológico o, si se quiere, el valor simbólico -y alegórico- que esas obras representan en el mercado de la identidad y de las ideas posmodernas.

Según ya he anotado, acaso también esté en la trastienda de esta campaña reivindicativa nada menos que el buensalvajismo relativista de Levi-Strauss, que tanto ha influido en la izquierda norteamericana y latinoamericana, puesto que su exaltación del pensamiento indígena y periférico frente al eurocentrismo occidental ha podido auspiciar una inversión de los valores y del sentido del circuito cultural América-Europa. Así como ya no habría sociedades avanzadas y atrasadas, tampoco existiría, para los antropólogos improvisados, un ascendiente de lo europeo sobre lo americano ${ }^{65}$; y hasta puede imaginarse el fenómeno inverso: las Indias Occidentales, América, Ultramar recuperan su antiquísimo predominio largamente perdido en una novedosa reconquista de la

64. Entiéndase que mi crítica va enderezada más hacia las lecturas parciales de la obra de Said por sus colegas postcolonialistas que hacia las teorías del ilustre profesor desaparecido de la Columbia University.

65. Para todo esto véase la deconstrucción filosófica que ha hecho el citado Sebreli de la antropología resentida y anti-occidental de Levi-Strauss, en un libro que lleva el expresivo título de El olvido de la razón (cap. 5). 
imaginación europea a la que, naturalmente, Cervantes, el gran paladín de la libertad de los oprimidos y del libre pensamiento, no puede permanecer ajeno.

En suma, el genial novelista parece haberse convertido, muy a su pesar y a despecho de los datos mismos presentes en su obra, en un arma arrojadiza en manos de una crítica voluntarista, prejuiciosa y politizada. Ésta pretende, en lo que se refiere a América, que los intolerables defectos -a los ojos de algunas cervantistas norteamericanas actuales- de su europeísmo mediterráneo y -en todo caso- de su matizado orientalismo, tienen que ser subsanados de inmediato. Como puede observarse, nuestras autoras han dislocado el caso cervantino con el fin de que sólo quepa una solución americana para un enigma que en realidad no existe como tal. Sin embargo, es evidente que los problemas de identidad, los ajustes de cuentas políticos o la deconstrucción posmoderna del campo de estudios del Siglo de Oro son cuestiones ajenas a Cervantes como caso histórico o como problema literario y que poco o nada resolveremos orientando artificialmente la lectura de sus obras hacia Occidente.

Para concluir, recordemos que Peter Carafiol ha hecho una interesante descripción de un panorama muy semejante, el de los estudios de norteamericanismo desde la Revolución Americana:

An offspring of nationalist cultural paranoia after the Revolution, American literary studies became an object of scholarship after the national centennial. For a century and a half the word America has been a critical singularity - a virtual bushel basket into which scholars have collected disparate texts, critical assumptions and practices, ideological positions, moral values, and profesional ambitions to give them the appearance of conceptual coherence. Laborers in a field divided by fiat from the territories of writing in English, generations of Americanists have agonized Bloomianly over its mission; speculated about what, if anything, makes the field coherent; plotted rationalizing myths of its origins and workings; and written version after version of its history, mostly to justify gestures that, with a remarkable lack of irony, mimic the engendering mythos of their subject by ritualistically discovering radically New (critical) Worlds (2011, p. 549).

\section{BIBLIOGRAFÍA}

Abellán, José Luis, La idea de América. Origen y evolución, Madrid, IberoamericanaVervuert, 2009.

Albistur, Jorge, Cervantes y la crónica de Indias, Montevideo, Uruguay, Ediciones de la Banda Oriental, 1989.

Albistur, Jorge, "Cervantes y América", Cuadernos hispanoamericanos, 463 (1989), pp. $65-72$.

Alborg, Juan Luis, Sobre crítica y críticos. Historia de la literatura española, Madrid, Gredos, 1991. 
Alonso, Carlos J., "The Burden of Modernity", en Doris Sommer, ed., The Places of History. Regionalism Revisited in Latin America (A Special Issue of Modern Language Quarterly), Modern Language Quarterly, 57.2 (junio de 1996), pp. 227-235.

Arciniegas, Germán, América en Europa, Buenos Aires, Editorial Sudamericana, 1975.

Arciniegas, German, "Don Quijote, un demócrata de izquierda", Revista de Occidente, 142 (1975), pp. 85-100 [recogido también en Jesús García Sánchez, antol., El Quijote visto desde América, Madrid, Visor, 2005, pp. 21-230].

Aznárez, Carlos, y NoRMA, Néstor, 500 años después. ¿descubrimiento o genocidio?, s. 1., Nuer Ediciones, 1992.

Bajtín, Mijail, Teoría y estética de la novela, Madrid, Taurus, 1989.

Bataillon, Marcel, Erasmo y España, México, Fondo de Cultura Económica, 1966.

Betancur, Belisario, "Cervantes y Don Quijote en las Indias", Revista de estudios cervantinos, 8 (2008), pp. 1-18 [consultado en www.estudioscervantinos.org, 2-2-12; también publicado en Guanajuato, 10 (1999), pp. 10-28].

Blanco-Fombona, Rufino, El conquistador español del siglo XVI, Caracas, Monte Ávila, 1993.

Bloom, Harold, El canon occidental. La escuela y los libros de todas las épocas, Barcelona, Anagrama, 1995 [orig. ing. 1994].

Brioso Santos, Héctor, "La figura del indiano teatral en el Siglo de Oro español", Actas del II Congreso Iberoamericano de Teatro. América y el teatro español del Siglo de Oro, Cádiz, Universidad, 1998, pp. 423-434.

Brioso Santos, Héctor, América en la prosa literaria española de los siglos XVI y XVII, Huelva, Diputación Provincial, 1999.

Brioso Santos, Héctor, coord., América en el teatro español del Siglo de Oro, Teatro, 15 (2001).

Brioso Santos, Héctor, "Novela, poliglotismo y americanismo: los poderes de la ficción o el nuevo cervantismo norteamericano", Quaderni Ibero-Americani, 98 (2005), pp. 5-32.

Brioso Santos, Héctor, "Diana de Armas Wilson, Cervantes, the Novel, and the New World (Oxford, Oxford University Press, 2003)", Hesperia, 8 (2005), pp. 161-174.

Brioso Santos, Héctor, Cervantes y América, Madrid, Marcial Pons, 2006 (con la colaboración de José Montero Reguera).

Brioso Sánchez, Máximo, y Brioso Santos, Héctor, "La picaresca y América en los Siglos de Oro", Anuario de Estudios Americanos, 49 (1993), pp. 207-232.

Brioso Sánchez, Máximo, y Brioso Santos, Héctor, "Sobre la problemática relación entre Heliodoro y el Persiles y Sigismunda de Cervantes: el motivo de la comunicación lingüística”, Criticón 86 (2002), pp. 73-96.

Brioso Sánchez, Máximo, y Brioso Santos, Héctor, "De nuevo sobre Cervantes y Heliodoro. La comunicación lingüística y algunas notas cronológicas", Cervantes 23.3 (2003), pp. 297-341.

Brioso Sánchez, Máximo, "El viaje en la novela griega antigua", en M. Brioso Sánchez y Antonio Villarrubia Medina, eds., Estudios sobre el viaje en la literatura de la Grecia antigua, Sevilla, Universidad de Sevilla, 2002, pp. 185-262.

Brioso Sánchez, Máximo, "La problemática de la comunicación lingüística en la novela griega antigua", Habis, 34 (2003), pp. 323-343.

Campos, Jorge, "Presencia de América en la obra de Cervantes", Revista de Indias, 8 (1947), pp. 371-404.

Canavaggio, Jean, Cervantes, Madrid, Espasa, 1997 [orig. fr., 1986]

Canavaggio, Jean, "Vida y literatura", en Don Quijote de la Mancha de Miguel de Cervantes, Francisco Rico (dir.), Barcelona, Crítica, 1998, xli-lxvi. 
Canavaggio, Jean, "Resumen cronológico de la vida de Cervantes", en Don Quijote de la Mancha de Miguel de Cervantes, Francisco Rico, dir., Barcelona, Crítica, 1998, ccxliii-cclxxi.

Carafiol, Peter, "Predicting the Past: The Paradoxes of American Literary History. By Michael Boyden", Modern Language Quarterly, 72.4 (diciembre de 2011), pp. 549-552.

Castillo, Moisés R., Indios en escena: la representación del amerindio en el teatro del Siglo de Oro, West Lafayette, Indiana, Purdue University Press, 2009.

Castro, Américo, Cervantes y los casticismos españoles, Madrid, Trotta, 2002 [1966].

Cervantes Saavedra, Miguel de, Don Quijote de la Mancha, Francisco Rico, dir., Barcelona, Crítica, 1998.

Childers, William, Transnational Cervantes, Toronto, University of Toronto Press, 2006.

Close, Anthony, The Romantic Approach to don Quijote. A Critical History of the Romantic Tradition in 'Quijote' Criticism, Cambridge, Cambridge University Press, 1978.

Close, Anthony, "Personalidad y cultura", en Francisco Rico (dir.), Don Quijote de la Mancha de Miguel de Cervantes, Barcelona, Crítica, 1998, pp. 1xvii-lxxxvi.

Cobos, Mercedes, Las Indias Occidentales en la poesía sevillana del Siglo de Oro, Sevilla, Universidad, 1997.

Correa Díaz, Luis, "América como Dulcinea. La salida transatlántica de Cervantes", Hispanic Journal, 21.2 (2000), pp. 459-480.

Close, Anthony, Cervantes y América / Cervantes en las Américas. Mapa de campo y ensayo de bibliografia razonada, Kassel-Barcelona, Reichenberger, 2006.

Defoe, Daniel, The Fortunes and Misfortunes of Moll Flanders, Londres, Penguin, 1996.

Delpech, Françoise, ed., L'imaginaire du territoire en Espagne et au Portugal (XVIe-XVII siècles), Madrid, Casa de Velázquez, 2009.

Diccionario enciclopédico de las letras de América Latina, Caracas, Monte Ávila, 1995.

Doody, Margaret Anne, "Heliodorus Rewritten: Samuel Richardson's Clarissa and Frances Burney's The Wanderer", Second International Conference on the Ancient Novel, Dartmouth College, 24-7-1989.

Doody, Margaret Anne, The True Story of the Novel, New Brunswick, Nueva Jersey, Rutgers University Press, 1996.

Eisenberg, Daniel, La biblioteca de Cervantes: una reconstrucción (versión preliminar de 2002, disponible en http://bigfoot.com/ daniel.eisenberg).

Elliott, John H., "Renaissance Europe and America: A Blunted Impact?", en Fredi Chiappelli et al., eds., First Images of America. The Impact of the New World on the Old, Berkeley, The University of California Press, 1976, I, pp. 11-23.

Ercilla y Zúñiga, Alonso, La Araucana, Marcos A. Morínigo e Isaías Lerner, eds., Madrid, Castalia, 1979.

Fernández, James D., "The Bonds of Patrimony: Cervantes and the New World", Papers of the Modern Language Association, 109.5 (1994), pp. 969-981.

Ferreras, Juan Ignacio, La novela en España. Historia, estudios y ensayos. I. Desde los orígenes a La Celestina, Colmenar Viejo, Ediciones del Laberinto, 2009.

Fogelquist, Donald F., Españoles de América y americanos de España, Madrid, Gredos, 1968.

Fuchs, Barbara, "Conquering Islands: Contextualizing The Tempest", Shakespeare Quarterly, 48 (1997), pp. 45-62.

Fuchs, Barbara, Mimesis and Empire: The New World, Islam, and European Identities, Cambridge, Cambridge University Press, 2001.

Fuchs, Barbara, "Cervantes, the Novel, and the New World", Modern Language Quarterly 63.4 (2002), pp. 537-539 (reseña). 
Fuchs, Barbara, Passing for Spain. Cervantes and the Fictions of Identity, University of Illinois Press, 2003.

Gaylord, Mary Malcolm, "El lenguaje de la conquista y la conquista del lenguaje en las poéticas del Siglo de Oro", Actas del IX Congreso de la Asociación Internacional de Hispanistas (18-23 agosto 1986, Berlín), Frankfurt am Main, Vervuert, 1989, pp. 469-475.

Gaylord, Mary Malcolm, The True History of Early Modern Writing in Spanish: Some American Reflections", en Doris Sommer, ed., The Places of History: Regionalism revisited in Latin America, Duke University Press, 1999, pp. 81-93 [también en The Places of History: Regionalism revisited in Latin America (A Special Issue of Modern Language Quarterly), Modern Language Quarterly, 57.2 (junio de 1996a), pp. 213235].

Gaylord, Mary Malcolm, "Don Quixote and the National Citizenship of Masterpieces", Marjorie Garber, Paul B. Franklin, Rebecca L. Walkowitz, eds., Field Work. Sites in Literary and Cultural Studies, Londres-Nueva York, Routledge, 1996b, pp. 97-105.

Gaylord, Mary Malcolm, "El Siglo de Oro y las Españas: propuesta de una nueva lectura americana del Quijote", Jules Whicker, coord., Estudios áureos, I, Actas del XII Congreso de la Asociación Internacional de Hispanistas, Birmingham, 21-26 de agosto de 1995, Birmingham, Dolphin Books, 1998, vol. II, pp. 237-242.

Gaylord, Mary Malcolm, "Don Quijote, Amadís y los héroes americanos de la palabra", El Quijote desde América, Gustavo Illades, y James Iffland, eds., Instituto de Ciencias Sociales y Humanidades Alfonso Vélez Pliego-Universidad Autónoma de Puebla, 2006, pp. 81-100.

Gaylord, Mary Malcolm, "Don Quixote's New World of Language", Cervantes: Bulletin of the Cervantes Society of America, 27.1 (spring 2007 [2008]), pp. 71-94.

O'Gorman, Edmundo, La invención de América, México, D.F., Fondo de Cultura Económica, 1995 [1958].

González Martínez, Elda, “América”, Gran enciclopedia cervantina, Carlos Alvar Ezquerra, coord., Madrid, Castalia-CEC, 2005-, I, pp. 495-496. La imagen del indio en la Europa moderna, Sevilla, CSIC, 1990.

Jameson, Fredric, "Third-World Literature in the Era of Multinational Capital", Social Text, 5.3 (1986), pp. 65-88.

Juaristi, Jon, El linaje de Aitor. La invención de la tradición vasca, Madrid, Taurus, 1987.

King, Willard F., “Cervantes' Numancia and Imperial Spain”, Modern Language Notes, 94 (1979), pp. 200-221.

Lerner, Isaías, "El Quijote y el lector americano", en Julio Vélez-Sainz y Nieves RomeroDíaz, eds., Cervantes and /on/in the New World, Newark, Delaware, Juan de la Cuesta, 2007, pp. 255-266.

Maestro, Jesús G., "Crítica de la idea de 'minoría' en la interpretación del Quijote", en Eduardo Urbina y J. G. Maestro, eds., Política y literatura. Miguel de Cervantes frente a la posmodernidad. Anuario de estudios cervantinos, V (2009), pp. 25-61.

Marichal, Juan, "The New World from Within: The Inca Garcilaso", en Fredi Chiappelli et al., eds., First Images of America. The Impact of the New World on the Old, Berkeley, The University of California Press, 1976, I, pp. 57-61.

Mariscal, George, "The Crisis of Hispanism as Apocalyptic Myth", en Anne J. Cruz Carroll B. Johnson, eds., Cervantes and his Postmodern Constituencies, Nueva York, Garland, 1998, pp. 201-217.

Mariscal, George, "Can Cultural Studies Speak Spanish?”, en Toby Miller (ed.), A Companion to Cultural Studies, Oxford, etc., Blackwell, 2001, pp. 232-245 [1994]. 
Márquez Villanueva, Francisco, Trabajos y días cervantinos, Alcalá de Henares, Centro de Estudios Cervantinos, 1995.

Márquez Villanueva, Francisco, "Prólogo", Américo Castro, Cervantes y los casticismos españoles, Obra reunida, vol. III, Madrid, Trotta, 2002, pp. 9-36.

Martínez Gil, Fernando, "La realidad histórica de una geografía imaginaria", Revista de libros, $\mathrm{n}^{\circ} 155$ (noviembre de 2009), pp. 12-13.

Martínez Torrón, Diego, y Dietz, Berndt, eds., Cervantes y el ámbito anglosajón, Madrid, Sial, 2005.

Medina, José Toribio, "Cervantes americanista: lo que dijo de los hombres y cosas de América", en Estudios cervantinos, Santiago de Chile, Fondo Histórico y Bibliográfico José Toribio Medina, 1958, pp. 507-537 [1915].

Mignolo, Walter D., "Linguistic Maps, Literary Geographies, and Cultural Landscapes: Languages, Languaging, and (Trans)nationalism", en Doris Sommer, ed., The Places of History: Regionalism revisited in Latin America, Duke University Press, 1999, pp. 49-65.

Mignolo, Walter D., "El metatexto historiográfico y la historiografía indiana", Modern Language Notes, 96 (1981), pp. 358-402.

Mojarro Romero, Jorge, "Cultural Studies: el pavoneo del emperador desnudo", http:// www.fororangel.com (publicado el 7-11-2009; consultado el 4-11-2010).

Montero Reguera, José, "La recepción del Quijote en Hispanoamérica (siglos XVII al XIX), Cuadernos Hispanoamericanos, 500 (1992), pp. 133-140.

Morínigo, Marcos A., América en el teatro de Lope de Vega, Buenos Aires, Universidad de Buenos Aires-Instituto de Filología, 1946.

Ortega, Julio, La cervantiada, Madrid, Ediciones Libertarias, 1993.

Pagden, Anthony, y Cruz, Manuel, El pasado y sus críticos, Madrid, Fundación Juan March, Cuadernos de Seminario Público (30 y 31 de mayo de 2001) (consultado en Internet, 10-3-2010).

Pardo, José Luis, "El conocimiento líquido. En torno a la reforma de las universidades públicas", Claves de razón práctica, $\mathrm{n}^{\circ} 186$ (octubre de 2008), pp. 4-11 (consultado en $\mathrm{H}:$ :José Luis Pardo El conocimiento líquido Sobre la reforma de las universidades públicas fírgoa.mht, 1-3-12).

Pastor Bodmer, Beatriz, Discurso narrativo de la conquista de América, La Habana, Ediciones Casa de las Américas, 1983.

Pastor Bodmer, Beatriz, "Hispanoamericanismo en Estados Unidos: viejos problemas y nuevas perspectivas", La otra orilla del español: las literaturas hispánicas de los Estados Unidos, Ínsula, no 667-668 (2002), pp. 10-13.

Pietschmann, Horst, "De La Invención de América a la historia como invención", Historia mexicana, 46.4 (1997), pp. 705-709.

Porras Barrenechea, Raúl, "Cervantes y el Perú: ¿La carta de un gobernador inspiró a Cervantes la célebre carta de Sancho Panza a su mujer Teresa Panza?”, Arbor, 3 (1945), pp. 537-544.

Porras Barrenechea, Raúl, El Inca Garcilaso en Montilla (1561-1614), Lima, San Marcos, 1955.

Rípodas Ardanaz, Daisy, antol. e introd.; Inmaculada Lapuista, transcrip., Lo indiano en el teatro menor español de los siglos XVI y XVII, Madrid, Atlas, 1991 (Biblioteca de Autores Españoles, vol. 301).

Rodó, José Enrique, Ariel. Motivos de Proteo, Ángel Rama, ed., Caracas, Biblioteca Ayacucho, 1976.

Rojas, Ricardo, Blasón de plata. Meditaciones y evocaciones sobre el abolengo de los argentinos, Buenos Aires, Martín García, 1912. 
Rojas, Ricardo, Cervantes, Buenos Aires, La Facultad, 1935.

Romero Muñoz, Carlos, ed., Los trabajos de Persiles y Sigismunda de Miguel de Cervantes, Madrid, Cátedra, 2002.

Said, Edward W., Orientalism, Nueva York, Pantheon Books, 1978.

Said, Edward W., Culture and Imperialism, Nueva York, Vintage, 1993.

Sánchez Albornoz, Claudio, España, un enigma histórico, Buenos Aires, Sudamericana, 1962 [1956].

Sebreli, Juan José, El olvido de la razón, Barcelona, Debate, 2007.

Simerka, Barbara, Discourses of Empire: Counter-Epic Literature in Early Modern Spain, University Park, Pennsylvania State University Press, 2003.

Sommer, Doris, "The Place of History: Regionalism Revisited in Latin America", Doris Sommer, ed., The Place of History: Regionalism Revisited (A Special Issue of Modern Language Quarterly), Modern Language Quarterly, 57.2 (junio de 1996), pp. 119-127.

Tenney, Tabitha G., "Descendientes del Quijote en América: Female Quixotism", en Diego Martínez Torrón y Berndt Dietz, eds., Cervantes y el ámbito anglosajón, Madrid, Sial, 2005, pp. 91-117.

Todorov, Tzvetan, Nosotros y los otros, México, Siglo XXI, 1991.

Tovar, Antonio, Lo medieval en la conquista y otros ensayos americanos, México, FCE, 1981 [1970].

Urtiaga, Alfonso, El indiano en la dramática de Tirso de Molina, Madrid, Revista Estudios, 1965.

Uslar Pietri, Arturo, En busca del Nuevo mundo, México, Fondo de Cultura Económica, 1969.

Wilson, Diana de Armas, "Cervantes's Last Romance: Deflating the Myth of Female Sacrifice”, Cervantes, 3 (1983), pp. 103-120.

Wilson, Diana de Armas, "Cervantes's Labors of Persiles: Working (in) the In-Between", en Patricia Parker y David Quint, eds., Literary Theory / Renaissance Texts, Baltimore and London, Johns Hopkins University Press, 1986, pp. 150-181.

Wilson, Diana de Armas, Allegories of Love: Cervantes's Persiles and Segismunda, Princeton, Princeton University Press, 1991.

Wilson, Diana de Armas, "'De gracia estraña': Cervantes, Ercilla y el Nuevo Mundo", en Georgina Dopico Black / Roberto González Echevarría, coords., En un lugar de la Mancha: estudios cervantinos en honor de Manuel Durán, Salamanca, Almar, 1999a, pp. 37-55.

Wilson, Diana de Armas, "Where Does the Novel Rise? Cultural Hybrids and Cervantes Heresies", en Anne J. Cruz and Carroll B. Johnson, Cervantes and his Postmodern Constituencies, Nueva York, Garland, 1999b, pp. 43-67.

Wilson, Diana de Armas, Cervantes, the Novel, and the New World, Oxford, Oxford University Press, 2003.

Wonham, Henry B., "Mark Twain: The American Cervantes”, en Darío Fernández-Morera y Michael Hanke, eds., Cervantes in the English-Speaking World: New Essays, Kassel, Reichenberger, 2005, pp. 159-161.

Yáñez, Agustín, "Introducción”, Crónicas de la conquista, México, UNAM, 1987, pp. v-Xvi [1939]. 
Recibido: 6 de marzo de 2012

Aceptado: 17 de enero de 2013

\title{
Resumen
}

Desde hace casi dos decadas, un grupo de cerventistas norteamericanas ha especulado con una interpretación americanista de las novelas de Miguel de Cervantes, en especial el Quijote y Persiles y Sigismunda. En el presente artículo, su autor analiza las bases ideológicas de tal hipótesis como una teoría arraigada en un posmodernismo crítico identitario.

Palabras clave: hispanismo, Miguel de Cervantes, identidad, subalternidad, periferia, crónicas de Indias, occidentalismo, transculturalidad, hibridismo, otredad, alegoría, historia, historia de la literatura, eurocentrismo.

Title: Tristes Tópicos cervantinos: periphery and identity in some postmodern approaches to Cervantes.

\begin{abstract}
For almost two decades, a group of North-american specialists in Cervantes have speculated americanist interpretation of Miguel de Cervantes' novels, and namely of Don Quixote and Persiles y Sigismunda. In this article, the author analyzes the ideological bases of such a hypothesis as a posmodern critical theory of identity.
\end{abstract}

Key words: hispanism, Miguel de Cervantes, identity, subalternity, periphery, chronicles of the Indies, occidentalism, tranculturatility, hibrids, otherness, political alegory, history, history of literature, eurocentrism 